NBER WORKING PAPER SERIES

\title{
THE INEFFICIENT MARKETS HYPOTHESIS: WHY FINANCIAL MARKETS DO NOT WORK WELL IN THE REAL WORLD
}

\author{
Roger E.A. Farmer \\ Carine Nourry \\ Alain Venditti \\ Working Paper 18647 \\ http://www.nber.org/papers/w18647 \\ NATIONAL BUREAU OF ECONOMIC RESEARCH \\ 1050 Massachusetts Avenue \\ Cambridge, MA 02138 \\ December 2012
}

This study is supported by French National Research Agency Grant (ANR-08-BLAN-0245-01) and was awarded the inaugural 2013 Maurice Allais Prize in Economic Science. We have presented versions of our work at the Federal Reserve Bank of San Francisco, the Federal Reserve Bank of St. Louis, the International Monetary Fund, the Paris School of Economics, Harvard University, the Bank of England, the London School of Economics, the European Central Bank, Bocconi University, Manchester University, Tsinghua University, the London Business School, Birmingham University, Brunel University, the University of Konstanz, the University of Bonn, the Barcelona GSE Summer School, the Stanford SITE conference, the 2013 PET conference in Lisbon, the 2013 SAET conference in Paris and the 2013 ASSET conference in Bilbao. We would like to thank Hippolyte d'Albis, Emmanuelle Augeraud-Véron, Antoine d'Autume, Bob Becker, Stefano Bosi, Ian Dew-Becker, Nick Bloom, John Cochrane, Jean-Pierre Drugeon, Frédéric Dufourt, Emmanuel Fahri, Aditya Goenka, Jean-Michel Grandmont, Thomas Hintermaier, Pamela Labadie, Cuong LeVan, Greg Mankiw, Alberto Martin, Bertrand Munier, Thomas Seegmuller, Jaume Ventura, Annette Vissing-Jorgensen, Ivan Werning and participants at these conferences and workshops for their valuable feedback. We also thank C. Roxanne Farmer for invaluable editorial assistance. The views expressed herein are those of the authors and do not necessarily reflect the views of the National Bureau of Economic Research.

NBER working papers are circulated for discussion and comment purposes. They have not been peerreviewed or been subject to the review by the NBER Board of Directors that accompanies official NBER publications.

(C) 2012 by Roger E.A. Farmer, Carine Nourry, and Alain Venditti. All rights reserved. Short sections of text, not to exceed two paragraphs, may be quoted without explicit permission provided that full credit, including $(\mathcal{C}$ notice, is given to the source. 
The Inefficient Markets Hypothesis: Why Financial Markets Do Not Work Well in the Real

World

Roger E.A. Farmer, Carine Nourry, and Alain Venditti

NBER Working Paper No. 18647

December 2012, Revised December 2013

JEL No. E44,G01,G12,G14

\section{ABSTRACT}

Existing literature continues to be unable to offer a convincing explanation for the volatility of the stochastic discount factor in real world data. Our work provides such an explanation. We do not rely on frictions, market in completeness or transactions costs of any kind. Instead, we modify a simple stochastic representative agent model by allowing for birth and death and by allowing for heterogeneity in agents' discount factors. We show that these two minor and realistic changes to the timeless Arrow-Debreu paradigm are sufficient to invalidate the implication that competitive financial markets efficiently allocate risk. Our work demonstrates that financial markets, by their very nature, cannot be Pareto efficient except by chance. Although individuals in our model are rational; markets are not.

Roger E.A. Farmer

UCLA

Department of Economics

Box 951477

Los Angeles, CA 90095-1477

and NBER

rfarmer@econ.ucla.edu

Carine Nourry

GREQAM

2 rue de la Charite

13236 Marseille cedex 02

France

and CNRS-GREQAM

carine.nourry@univmed.fr

\author{
Alain Venditti \\ GREQAM \\ 2 rue de la Charite \\ 13236 Marseille cedex 02 \\ France \\ and CNRS-GREQAM \\ alain.venditti@univmed.fr
}




\title{
THE INEFFICIENT MARKETS HYPOTHESIS: WHY FINANCIAL MARKETS DO NOT WORK WELL IN THE REAL WORLD
}

\author{
ROGER E.A. FARMER, CARINE NOURRY AND ALAIN VENDITTI
}

\begin{abstract}
Existing literature continues to be unable to offer a convincing explanation for the volatility of the stochastic discount factor in real world data. Our work provides such an explanation. We do not rely on frictions, market incompleteness or transactions costs of any kind. Instead, we modify a simple stochastic representative agent model by allowing for birth and death and by allowing for heterogeneity in agents' discount factors. We show that these two minor and realistic changes to the timeless Arrow-Debreu paradigm are sufficient to invalidate the implication that competitive financial markets efficiently allocate risk. Our work demonstrates that financial markets, by their very nature, cannot be Pareto efficient, except by chance. Although individuals in our model are rational; markets are not.
\end{abstract}

\section{INTRODUCTION}

Discount rates vary a lot more than we thought. Most of the puzzles and anomalies that we face amount to discount-rate variation we do not understand. Our theoretical controversies are about how discount rates are formed. Cochrane (2011, Page 1091).

Date: November 4, 2013.

This study is supported by French National Research Agency Grant (ANR-08-BLAN-0245-01) and was awarded the inaugural 2013 Maurice Allais Prize in Economic Science. We have presented versions of our work at the Federal Reserve Bank of San Francisco, the Federal Reserve Bank of St. Louis, the International Monetary Fund, the Paris School of Economics, Harvard University, the Bank of England, the London School of Economics, the European Central Bank, Bocconi University, Manchester University, Tsinghua University, the London Business School, Birmingham University, Brunel University, the University of Konstanz, the University of Bonn, the Barcelona GSE Summer School, the Stanford SITE conference, the 2013 PET conference in Lisbon, the 2013 SAET conference in Paris and the 2013 ASSET conference in Bilbao. We would like to thank Hippolyte d'Albis, Emmanuelle Augeraud-Véron, Antoine d'Autume, Bob Becker, Stefano Bosi, Ian Dew-Becker, Nick Bloom, John Cochrane, Jean-Pierre Drugeon, Frédéric Dufourt, Emmanuel Fahri, Aditya Goenka, Jean-Michel Grandmont, Thomas Hintermaier, Pamela Labadie, Cuong Le Van, Greg Mankiw, Alberto Martin, Bertrand Munier, Thomas Seegmuller, Jaume Ventura, Annette Vissing-Jorgensen, Ivan Werning and participants at these conferences and workshops for their valuable feedback. We also thank C. Roxanne Farmer for invaluable editorial assistance. 
Since the work of Paul Samuelson and Eugene Fama, writing in the 1960's, (Samuelson, 1963; Fama, 1963, 1965a,b), the efficient markets hypothesis (EMH) has been the starting point for any discussion of the role of financial markets in the allocation of risk. In his 1970 review article, Fama (1970) defines an efficient financial market as one that "reflects all available information". If markets are efficient in this sense, uninformed traders cannot hope to profit from clever trading strategies. To reflect that idea we say there is "no free lunch".

Although the efficient markets hypothesis is primarily about the inability to make money in financial markets, there is a second implication of the EMH that follows from the first welfare theorem of general equilibrium theory; this is the idea that complete, competitive financial markets lead to Pareto efficient allocations. Richard Thaler, (2009), writing in a review of Justin Fox's (2009) book, The Myth of the Rational Market, refers to this second dimension of the EMH as "the price is right".

We argue here that competitive financial markets do not lead to Pareto efficient outcomes, except by chance, and that the failure of complete financial markets to deliver socially efficient allocations has nothing to do with financial constraints, transactions costs or barriers to trade. We show that the first welfare theorem fails in any model of financial markets that reflects realistic population demographics. Although individuals in our model are rational; markets are not.

In their seminal paper, Cass and Shell (1983) differentiate between uncertainty generated by shocks to preferences, technology or endowments - intrinsic uncertainty - and shocks that do not affect any of the economic fundamentals - extrinsic uncertainty. When consumption allocations differ in the face of extrinsic uncertainty, Cass and Shell say that sunspots matter. Our paper demonstrates that the existence of equilibria with extrinsic uncertainty has important practical implications for real world economies. We show that sunspots really do matter: And they matter in a big way in any model that is calibrated to fit realistic probabilities of birth and death.

The paper is structured as follows. Sections II and III explain how our findings are connected with the literature on the excess volatility of stock market prices. Section IV provides an informal description of our model along with a description of our main results. Section $\mathrm{V}$ provides a series of definitions, lemmas and propositions that formalize our results. In Section VI, we provide some computer simulations of the invariant distribution implied by our model for a particular calibration. Finally, Section VII presents a short conclusion and a summary of our main ideas. 


\section{Related Literature}

Writing in the early 1980s, Leroy and Porter (1981) and Shiller (1981) showed that the stock market is too volatile to be explained by the asset pricing equations associated with complete, frictionless financial markets. The failure of the frictionless Arrow-Debreu model to explain the volatility of asset prices in real world data is referred to in the literature as 'excess volatility'.

To explain excess volatility in financial markets, some authors introduce financial frictions that prevent rational agents from exploiting Pareto improving trades. Examples include, Bernanke and Gertler (1989, 2001); Bernanke, Gertler, and Gilchrist (1996) and Carlstom and Fuerst (1997) who have developed models where net worth interacts with agency problems to create a financial accelerator.

An alternative way to introduce excess volatility to asset markets is to drop aspects of the rational agents assumption. Examples of this approach include Barsky and DeLong (1993), who introduce noise traders, Bullard, Evans, and Honkapohja (2010) who study models of learning where agents do not have rational expectations and Lansing (2010), who describes bubbles that are 'near-rational' by dropping the transversality condition in an infinite horizon framework.

It is also possible to explain excess volatility by moving away from a standard representation of preferences as the maximization of a time separable Von-Neuman Morgenstern expected utility function. Examples include the addition of habit persistence in preferences as in Campbell and Cochrane (1999), the generalization to non time-separable preferences as in Epstein and Zin $(1989,1991)$ and the models of behavioral finance surveyed by Barberis and Thaler (2003).

In a separate approach, a large body of literature follows Kiyotaki and Moore (1997) who developed a model where liquidity matters as a result of credit constraints. A list of papers, by no means comprehensive, that uses related ideas to explain financial volatility and its effects on economic activity would include the work of Abreu and Brunnermeier (2003); Brunnermeir (2012); Brunnermeir and Sannikov (2012); Farmer (2013); Fostel and Geanakoplos (2008); Geanakoplos (2010); Miao and Wang (2012); $\mathrm{Gu}$ and Wright (2010) and Rochetau and Wright (2010).

There is a further literature which includes papers by Caballero and Krishnamurthy (2006); Fahri and Tirole (2012) and Martin and Ventura (2011, 2012), that explains financial volatility and its effects using the overlapping generations model. Our work differs from this literature. Although we use a version of the overlapping generations framework, our results do not rely on frictions of any kind. 
Models of financial frictions have received considerable attention in the wake of the 2008 recession. But models in this class have not yet been able to provide a convincing explanation for the size and persistence of the rate of return shocks that are required to explain large financial crises. The importance of shocks of this kind is highlighted by the work of Christiano, Motto, and Rostagno (2012), who estimate a dynamic stochastic general equilibrium model with a financial sector. They find that a shock they refer to as a "risk shock" is the most important driver of business cycles. In effect, the risk shock changes the rate at which agents discount the future.

New Keynesian explanations of financial crises also rely on a discount rate shock and, to explain the data following major financial crises, this shock must be large and persistent (Eggertsson and Woodford, 2002; Eggertsson, 2011). Eggertsson (2011), for example, requires a $5.47 \%$ annualized shock to the time preference factor to account for the large output and inflation declines that occurred following the stock market crash of 1929.

The literature reviewed in this section continues to be unable to offer a convincing explanation for volatility of the stochastic discount factor of the magnitude that is required to explain real world data. This work provides such an explanation. Our explanation is simple and general and the logic of our argument applies to any model of financial markets with realistic population demographics.

We do not rely on frictions, market incompleteness or transactions costs of any kind. Instead, we modify a simple stochastic representative agent model by allowing for birth and death and by allowing for heterogeneity in agents' discount factors. We show that these two minor, and realistic, changes to the timeless Arrow-Debreu paradigm are sufficient to invalidate the implication that competitive financial markets efficiently allocate risk. Our work demonstrates that financial markets, by their very nature, cannot be Pareto efficient, except by chance. In our model, financial markets do not work well because population demographics close down the insurance opportunities that are required to support optimality. Our framework is able to replicate the volatility of the stochastic discount factor that we observe in real world data; this fact suggests that financial markets are not only Pareto inefficient in our model, they are Pareto inefficient in the real world.

\section{WHY EQUILIBRIA ARE INEFFICIENT}

Inefficiency occurs in overlapping generations models for two reasons. First, $d y$ namic inefficiency occurs because there is a double infinity of agents and commodities. 
Second, sunspot inefficiency occurs because agents are unable to insure against events that occur before they are born.

It has long been understood that the overlapping generations model, (Allais 1947, Samuelson 1958) leads to equilibria that are dynamically inefficient. ${ }^{1}$ The cause of that inefficiency was identified by Shell (1971) who showed that, even if all agents could trade contingent commodities at the beginning of time, the non-stochastic OLG model would still contain equilibria that are dynamically inefficient. The first welfare theorem fails in that environment because the wealth of all individuals is finite in an inefficient equilibrium even when social wealth is unbounded. We do not rely on dynamic inefficiency in this paper, and in the absence of uncertainty, our model has a unique dynamically efficient equilibrium.

The second source of inefficiency in overlapping generations models arises from the absence of insurance opportunities. In their (1983) paper, Cass and Shell showed that equilibria may be inefficient if some agents are unable to participate in markets that open before they are born and Azariadis (1981) provided a dynamic example of a model where sunspots influence economic activity. ${ }^{2}$ The example that Cass and Shell provided in the body of their paper relied on the existence of multiple equilibria in the underlying, non-stochastic economy. As a result, the majority of the work on sunspots that followed Cass and Shell and Azariadis has sought to construct examples of models where there are multiple equilibria in the underlying economy as in the work of Farmer and Woodford (1984, 1997), Benhabib and Farmer (1994); Farmer and Guo (1994), Farmer (1999, 2010, 2014) and Wen (1998).

We build on this literature. Unlike previous papers that have constructed calibrated examples of sunspot models, our work does not rely on randomizing over the multiple equilibria of an underlying non-stochastic model. Instead, as in Farmer (2012b), and the example constructed in the appendix to Cass and Shell (1983), equilibrium in the non-stochastic version of our model is unique.

\footnotetext{
${ }^{1}$ See Malinvaud (1987) for a discussion of the genesis of the history of the overlapping generations model. Although the model is often attributed to Samuelson (1958) it appears earlier in the Appendix 2 to Allais' book, Economie et Intérêt (1947). Allais also provides the first discussion of the optimal rate of capital accumulation, later known as the Golden Rule (Swan 1956, Phelps 1961).

${ }^{2}$ Cass and Shell (1983) distinguished between ex ante and ex post optimality. Ex post optimality distinguishes between the same person, call him Mr. $A(S)$ who is born into state of the world $S$ and Mr. $A\left(S^{\prime}\right)$ who is the same person born into the state of the world $S^{\prime}$. Using an ex post Pareto criterion, sunspot equilibria are Pareto optimal because people born into different states of the world are different people. In this paper, we adopt an ex-ante definition of Pareto efficiency.
} 
Angeletos and La'O (2013) and Benhabib, Wang, and Wen (2012) also construct sunspot models where there is a unique underlying equilibrium. Unlike their work, however, our model does not rely on informational frictions, nor do we assume that there are credit constraints, borrowing constraints or liquidity constraints. Significantly, our only departure from a frictionless, timeless, Arrow Debreu model is the assumption that agents cannot participate in financial markets that open before they are born.

When agents have realistic death probabilities and discount factors ranging from $2 \%$ to $10 \%$, we find that the human wealth of new-born agents can differ by a factor of $25 \%$ depending on whether they are born into a boom or into a recession. These numbers are similar in magnitude to the long-term costs of job loss reported by Oreopoulos, Von-Wachter, and Heisz (2012) in their study of the effects of severe recessions. Although we do not provide an explicit model of unemployment in this paper, related work by Farmer (2010, 2012a,c, 2013), Farmer and Plotnikov (2012) and Plotnikov (2012) does provide a mechanism that translates asset price shocks into persistent unemployment. This body of research, in conjunction with the current paper, provides an explanation for the large welfare costs of business cycles that Oreopoulos, Von-Wachter and Heisz find in the data.

\section{An INFORMAL DESCRIPTiOn OF THE ENVIRONMENT}

This section provides an informal description of our model. We study a pure trade economy with a stochastic aggregate endowment, $\omega_{t}$, that we refer to interchangeably as income or GDP. Our economy is populated by patient type 1 agents and impatient type 2 agents. Time is discrete and, as in Blanchard (1985), both types survive into period $t+1$ with age invariant probability $\pi$. Each type maximizes the expected present discounted value of a logarithmic utility function. These assumptions allow us to find simple expressions for the aggregate consumption of type $i \in\{1,2\}$ as a function of type $i$ 's wealth.

We model a stationary population by assuming that in every period a fraction $(1-\pi)$ of each type dies and is replaced by a fraction $(1-\pi)$ of newborns of the same type. Agents are selfish and do not leave bequests to their descendents. Type 1 agents own a fraction $\mu$ of the aggregate endowment and type 2 agents own a fraction $1-\mu$.

We assume that there is a perfect annuities market, mediated by a set of competitive, zero-profit, financial intermediaries. Agents borrow and lend to financial intermediaries at a gross interest rate that exceeds the market rate. If an agent dies 
with positive financial wealth, the agent's assets are returned to the financial intermediary, and on the other side of this market, agents who borrow are required to take out life insurance contracts that settle their debts when they die.

IV.1. Our main results. Our work builds on earlier work (Farmer, 2002a,b; Farmer, Nourry, and Venditti, 2011) which developed methods for adding aggregate uncertainty to Blanchard's (1985) perpetual youth model. Here, we apply the results of these earlier works to characterize equilibria as a pair of stochastic difference equations in two state variables that we call $z_{1, t}$ and $z_{t}$.

The variable $z_{1, t}$ is the present discounted value of the endowment of all living type 1 agents, divided by aggregate GDP. The variable $z_{t}$ is the present discounted value of the endowments of all living agents, (both type 1 and type 2) divided by aggregate GDP. We call these variables, the type 1 human wealth ratio and the aggregate human wealth ratio.

Let $S_{t}$ be a vector of random variables realized at date $t$ that may be influenced by either intrinsic or extrinsic uncertainty and let $S^{t} \equiv\left\{S_{0}, S_{1} \ldots S_{t}\right\}$ be the history of realizations of $S$ from date 0 to date $t$. Subscripts denote date $t$ realizations of $S$ and superscripts denote histories.

We define the pricing kernel, $Q_{t}^{t+1}\left(S^{t+1}\right)$ to be the price paid at date $t$ in history $S^{t}$, in units of consumption, for delivery of one unit of the consumption commodity at date $t+1$ in state $S_{t+1}$. We define a second variable

$$
\tilde{Q}_{t}^{t+1}\left(S^{t+1}\right)=Q_{t}^{t+1}\left(S^{t+1}\right) \frac{\gamma\left(S^{t+1}\right)}{\psi\left(S^{t+1}\right)}
$$

where

$$
\gamma\left(S^{t+1}\right) \equiv \frac{\omega_{t+1}\left(S^{t+1}\right)}{\omega_{t}\left(S^{t}\right)},
$$

is endowment growth in history $S^{t+1}$ and

$$
\psi\left(S^{t+1}\right)
$$

is the probability that state $S_{t+1}$ occurs conditional on history $S^{t}$. We refer to $\tilde{Q}_{t}^{t+1}\left(S^{t+1}\right)$ as the normalized pricing kernel.

The main contribution of our paper is a direct application of the results of Farmer, Nourry, and Venditti (2011), who derive an expression for the normalized pricing kernel as a function of the aggregate human wealth ratio at date $t$ and the type 1 human wealth ratio at date $t+1$,

$$
\tilde{Q}_{t}^{t+1}=\tilde{Q}\left(z_{t}, z_{1, t+1}\right) .
$$

Their result follows from the following argument. 
The model has two types of agents, each with logarithmic preferences. Consider an agent of type $i$, born at date $j \leq t$. The consumption plan of this agent $\left\{c_{i, t}^{j}\right\}_{t \geq j}$ must satisfy the following first order condition for each pair of consecutive histories, $\left\{S^{t}, S^{t+1}\right\}$

$$
Q_{t}^{t+1}\left(S^{t+1}\right)=\frac{\psi\left(S^{t+1}\right) \beta_{i} c_{i, t}^{j}\left(S^{t}\right)}{c_{i, t+1}^{j}\left(S^{t+1}\right)} .
$$

We can add up this expression over all type $i$ agents alive at date $t$ to give

$$
Q_{t}^{t+1}\left(S^{t+1}\right)=\frac{\psi\left(S^{t+1}\right) \beta_{i} C_{i, t}\left(S^{t}\right)}{\bar{C}_{i, t+1}\left(S^{t+1}\right)},
$$

where $C_{i, t}\left(S^{t}\right)$ is the consumption of all type $i$ agents alive at date $t$. Note however, that $\bar{C}_{i, t+1}\left(S^{t+1}\right)$ is not the consumption of all type $i$ agents alive at date $t+1$; it is the consumption of the subset of those agents who were also alive at date $t$. The difference is that between periods $t$ and $t+1$, some agents died and some new agents were born. We seek an expression for $\bar{C}_{i, t+1}\left(S^{t+1}\right)$ in terms of variables we can observe. To find such an expression we note that

$$
\bar{C}_{i, t+1}\left(S^{t+1}\right)=C_{i, t+1}\left(S^{t+1}\right)-C_{i, t+1}^{t+1}\left(S^{t+1}\right),
$$

where $C_{i, t+1}\left(S^{t+1}\right)$ is the aggregate consumption of all type $i$ agents alive in history $S^{t+1}$ and $C_{i, t+1}^{t+1}\left(S^{t+1}\right)$ is the consumption in history $S^{t+1}$ of the new born agents.

To complete the argument we note that Equation (6) holds for type 1 and type 2 agents and we make use of four facts. First, the goods market must clear. This implies that

$$
C_{1, t}\left(S^{t}\right)+C_{2, t}\left(S^{t}\right)=\omega_{t}
$$

for all histories $S^{t}$. Second, the assumption of logarithmic preferences implies that consumption of each type is linear in wealth; this fact implies that,

$$
C_{i, t}\left(S^{t}\right)=B_{i}\left[a_{i, t}\left(S^{t}\right)+h_{i, t}\left(S^{t}\right)\right]
$$

where $h_{i t} \equiv z_{i t} \omega_{t}$ is the human wealth of all type $i$ agents, $a_{i, t}$ is the financial wealth held by agents of type $i$ and $B_{i}$ is a parameter that depends on type $i^{\prime} s$ discount factor and the survival probability. Third, asset market clearing implies that

$$
a_{1, t}\left(S^{t}\right)+a_{2, t}\left(S^{t}\right)=0
$$

Finally, the assumption of no bequests implies that the consumption of new-born agents is linear in human wealth. Putting all of these pieces together allows us to 
derive an expression for $\tilde{Q}_{t}^{t+1}\left(S^{t}\right)$ as a rational polynomial in the aggregate human wealth ratio at date $t$ and the type 1 human wealth ratio at date $t+1$,

$$
\tilde{Q}\left(z_{t}, z_{1, t+1}\right)=\frac{-1}{\pi}\left(\frac{\theta_{4}+\theta_{2} z_{t}}{1+\theta_{3} z_{1, t+1}}\right),
$$

where $\theta_{2}, \theta_{3}$ and $\theta_{4}$ are known functions of the four structural parameters, $\mu, \beta_{1}, \beta_{2}$ and $\pi$.

By applying this expression to the definitions of the type 1 human wealth ratio and to the aggregate human wealth ratio, we are able to characterize equilibria as solutions to the following pair of stochastic difference equations,

$$
\begin{aligned}
z_{1, t} & =\mu+E_{t}\left\{\pi \tilde{Q}\left(z_{t}, z_{1, t+1}\right) z_{1, t+1}\right\}, \\
z_{t} & =1+E_{t}\left\{\pi \tilde{Q}\left(z_{t}, z_{1, t+1}\right) z_{t+1}\right\} .
\end{aligned}
$$

Notice that, although the endowment fluctuates, Equations (12) and (13) do not explicitly involve terms in the random aggregate endowment. Although human wealth is a random variable, there is an equilibrium in which the human wealth ratio is not. This equilibrium is represented by a non-stochastic solution to Equations (12) and (13).

Not all sequences that solve equations (12) and (13) are consistent with market clearing because very high or very low values of human wealth would require negative consumption of one of the two types. If a sequence is consistent with an interior equilibrium at all points in time we say that the solution is admissible. We prove that the non-stochastic system represented by the equations

$$
\begin{gathered}
z_{1, t}=\mu+\pi \tilde{Q}\left(z_{t}, z_{1, t+1}\right) z_{1, t+1}, \\
z_{t}=1+\pi \tilde{Q}\left(z_{t}, z_{1, t+1}\right) z_{t+1}
\end{gathered}
$$

has a unique admissible steady state which is a saddle. We show further that the model has a single initial condition represented by the human wealth ratio of type 1 agents at date 0 . It follows, that the model has a unique fundamental equilibrium, represented by the stable branch of the saddle.

We derive an explicit closed-form solution for the equation that characterizes this equilibrium. This solution is a first order difference equation in $z_{t}$, found by replacing $z_{1, t}$ in Equations (14) and (15) with the equality,

$$
z_{1, t}=\mu z_{t}
$$


at all dates. This substitution leads to a function, $g(\cdot)$ for the stable branch of the saddle which is found by solving the equation

$$
z_{t}=1+\pi \tilde{Q}\left(z_{t}, \mu z_{t+1}\right) z_{t+1},
$$

for $z_{t+1}$ as a function of $z_{t}$. Given this function, the sequence $\left\{z_{t}\right\}$, defined as the unique solution to the difference equation

$$
z_{t+1}=g\left(z_{t}\right), \quad z_{0}=\bar{z}_{0},{ }^{3}
$$

is an equilibrium of our model economy. The initial condition is determined by asset and goods market clearing in the first period and it is natural to impose an initial condition where agents of type 1 and type 2 are each born with zero financial obligations. We refer to the sequence $\left\{z_{t}\right\}$, constructed in this way, as the fundamental equilibrium of our model economy.

IV.2. Properties of the fundamental equilibrium. The fundamental equilibrium has the following properties. Given the initial value $z_{0}$, human wealth converges to a unique steady state value, $z^{*}$, and once this steady state has been reached, the normalized pricing kernel remains constant at a fixed value $\tilde{Q}^{*}$.

Recall that the pricing kernel is defined by the expression,

$$
Q_{t}^{t+1}=\tilde{Q}^{*} \frac{\gamma}{\psi}
$$

where $\tilde{Q}^{*}$ is the value of the normalized pricing kernel at the steady state. This equation implies that, in the fundamental equilibrium, the price of an Arrow security will fluctuate in proportion to shocks to the stochastic endowment process. This mirrors the pricing equation associated with a representative agent economy where the agent has logarithmic preferences and where $\tilde{Q}^{*}$ plays the role of the representative agent's discount factor.

In the fundamental equilibrium, all uncertainty is intrinsic. Newborn agents trade a complete set of Arrow securities with financial intermediaries, and depending on type, these agents may start life as net borrowers (these are the type 2 agents) or net lenders (these are the type 1 agents). As time progresses, the measure of agents born at date $t$ shrinks exponentially and the age distribution of each type converges to an exponential distribution. Long-lived type 1 agents eventually consume more than their endowments as they accumulate financial assets. Long-lived type 2 agents

\footnotetext{
${ }^{3}$ The initial values of the human wealth ratio of type 1 agents and the aggregate human wealth ratio are related as $\bar{z}_{1,0}=\mu \bar{z}_{0}$.
} 
eventually consume less than their endowments as they devote an ever larger fraction of their incomes to debt repayment.

IV.3. Equilibria where sunspots matter. Imagine an economy with no fundamental uncertainty that has attained the fundamental steady state equilibrium. Now suppose that at some special date, date $T$, it is common knowledge that a prominent financial journalist will write an article that has important implications for the asset markets. The journalist is credible and his pronouncement will be believed and acted upon. There are two possible states of the world that may occur at date $T$. If state $a$ occurs, the journalist will make a pessimistic pronouncement. In that event, the stochastic discount factor will be low, the real interest rate will be high, and the value of human wealth at date $T$ will be low. In state $b$, the journalist will make an optimistic pronouncement. In that event, the value of the stochastic discount factor will be high (close to 1), the real interest rate will be low, and the value of human wealth will be high. In both states, the normalized stochastic discount factor, following the shock, will converge back slowly to its steady state value $\tilde{Q}^{*}$.

It is important to note that nothing real has changed across states $a$ and $b$. The economy, by assumption, has a single unit of the endowment in every period. The ownership of this unit is split between three groups; type 1 agents alive at date $T-1$, type 2 agents alive at date $T-1$, and the new born agents of both types. We show in this paper that, even when the first two groups can write insurance contracts contingent on the realization of the announcement; there will still exist an equilibrium in which the announcement has real effects. The reason for the existence of this nonfundamental equilibrium is that the unborn agents are unable to participate in the insurance market that opens before they are born.

Suppose that state $a$ occurs. Then the new-born agents are born into a state of the world in which they are poor. Because the endowment is unchanged, this fact implies that there has been a wealth transfer from the unborn to the existing agents. And because these agents have different rates of time preference, the patient agents will increase their lending to the impatient agents. If state $b$ occurs, the reverse happens. In this state there is wealth transfer from the existing agents to the unborn, and since both types are now poorer, the patient agents will lend less to the impatient types. We show that this desire to change the amounts borrowed or lent across states is exactly enough to make the change in the stochastic discount factor self-fulfilling.

One might conjecture that this effect cannot be very large if the model is calibrated to reasonable parameter values. That conjecture would be mistaken. We calibrate the average life expectancy to 50 years, the discount rates to $2 \%$ and $10 \%$ and the 
fraction of patient agents to $50 \%$. With this calibration we are able to generate non-fundamental equilibria in which the human wealth of a new born agent can differ by $25 \%$ across states. The reason for this huge effect is that the stochastic discount factor is incredibly persistent. It is not just the $2 \%$ of agents born in each year, that cannot insure against the shock; it is all future agents that will be affected by a shock that dies out very slowly. We think that this feature of our model captures the real world fact that financial crises are persistent and generate large intergenerational transfers.

In our paper, we capture the effects of non-fundamental shocks by adding repeated sunspot shocks of this kind. We show that our model has many sunspot equilibria, represented by stochastic processes for $z_{t}$ that satisfy the following analog of Equation (17).

$$
z_{t}=1+E_{t}\left\{\pi \tilde{Q}\left(z_{t}, \mu z_{t+1}\right) z_{t+1}\right\}
$$

We construct these equilibria by multiplying $\tilde{Q}$ in Equation (20) by a mean 1 random variable, $\varepsilon_{s, t+1}$, and solving the resulting expression for a function

$$
z_{t+1}=g\left(z_{t}, \varepsilon_{s, t+1}\right)
$$

that describes a class of sunspot equilibria.

\section{A Formal DESCRIPtion of the ENVIRONMENT}

This section consists of a series of formal definitions, propositions and lemmas that establish formally, the properties described in Section IV.

Uncertainty each period is indexed by a finite set of states $\mathbf{S}=\left\{S_{1}, \ldots, S_{n}\right\}$. Define the set of $t$-period histories $\mathbf{S}^{t}$ recursively as follows:

$$
\begin{aligned}
& \mathbf{S}^{1}=\mathbf{S} \\
& \mathbf{S}^{t}=\mathbf{S}^{t-1} \times \mathbf{S}, \quad t=2, \ldots
\end{aligned}
$$

We will use $S_{t}$ to denote a generic element of $\mathbf{S}$ realized at date $t, S^{t}$ to denote an element of $\mathbf{S}^{t}$ realized at $t$ and $\left|\mathbf{S}^{t}\right|$ to denote the number of elements in $\mathbf{S}^{t}$. Let the probability that $S_{t+1}$ occurs at date $t+1$, conditional on history $S^{t}$, be given by $\psi\left(S^{t+1}\right)$ and assume that this probability is independent of time.

We define $\beta_{i}$ to be the discount factor of type $i$ and we assume

$$
0<\beta_{2}<\beta_{1}<1 \text {. }
$$

Throughout the paper, we use the following transformed parameters,

$$
B_{i} \equiv\left(1-\beta_{i} \pi\right)
$$


and from Equation (23) it follows that,

$$
B_{2}>B_{1}
$$

A household of type $i$, born at date $j$, solves the problem,

$$
\max E_{j}\left\{\sum_{t=j}^{\infty}\left(\pi \beta_{i}\right)^{t-j} \log c_{i, t}^{j}\left(S^{t}\right)\right\},
$$

such that

$$
\begin{gathered}
\sum_{S_{t+1} \in \mathbf{S}}^{|\mathbf{S}|} \pi Q_{t}^{t+1}\left(S^{t+1}\right) a_{i, t+1}^{j}\left(S^{t+1}\right) \leq a_{i, t}^{j}\left(S^{t}\right)+\omega_{i, t}\left(S^{t}\right)-c_{i, t}^{j}\left(S^{t}\right), \quad t=j, \ldots \\
a_{i, j}^{j}\left(S^{j}\right)=0 .
\end{gathered}
$$

The solution to this problem satisfies the Euler equation

$$
Q_{t}^{t+1}\left(S^{t+1}\right)=\frac{\psi\left(S^{t+1}\right) \beta_{i} c_{i, t}^{j}\left(S^{t}\right)}{c_{i, t+1}^{j}\left(S^{t+1}\right)},
$$

for each history $S^{t}$ and each of its $|\mathbf{S}|$ successors $S_{t+1}$, where $c_{i, t}^{j}\left(S^{t}\right)$ is the consumption at date $t$ in history $S^{t}$, of a member of type $i$, born at date $j$, and $a_{i, t}^{j}\left(S^{t}\right)$ is the agent's financial wealth.

Let $h_{i, t}\left(S^{t}\right)$ be type $i^{\prime} s$ human wealth, defined as

$$
h_{i, t}\left(S^{t}\right)=\omega_{i, t}\left(S^{t}\right)+\pi \sum_{S_{t+1}} Q_{t}^{t+1}\left(S^{t+1}\right) h_{i, t+1}\left(S^{t+1}\right), \quad t=0, \ldots
$$

Since each member of type $i$ has the same endowments and the same probability of dying, the human wealth of all members of type $i$ will be the same across generations. We assume that

$$
\lim _{T \rightarrow \infty} \pi^{T-1} Q_{t}^{T}\left(S^{T}\right) \omega_{i, T}\left(S^{T}\right)=0, \text { for all } S^{T} \in \mathbf{S}^{T},
$$

which implies that human wealth is well defined and can be represented as the net present value of future endowments summed over all possible future histories,

$$
h_{i, t}\left(S^{t}\right)=\sum_{\tau=t}^{\infty} \sum_{S^{\tau} \in \mathbf{S}^{\tau}}^{\left|\mathbf{S}^{\tau}\right|} \pi^{\tau-t} Q_{t}^{\tau}\left(S^{\tau}\right) \omega_{i, \tau}\left(S^{\tau}\right) .
$$

Using these results and the properties of logarithmic preferences, we have that,

$$
c_{i, t}^{j}\left(S^{t}\right)=B_{i}\left[a_{i, t}^{j}\left(S^{t}\right)+h_{i, t}^{j}\left(S^{t}\right)\right] .
$$

Next, we apply the methods developed in Farmer, Nourry, and Venditti (2011) to find the following expression for the pricing kernel, 
Proposition 1. The pricing kernel can be expressed as

$$
Q_{t}^{t+1}\left(S^{t+1}\right)=\frac{\psi\left(S^{t+1}\right)\left(1-B_{i}\right) C_{i, t}\left(S^{t}\right)}{C_{i, t+1}\left(S^{t+1}\right)-B_{i}(1-\pi) h_{i, t+1}\left(S^{t+1}\right)}
$$

where $C_{i, t}\left(S^{t}\right)$ is the aggregate consumption of all agents of type $i$ alive at date $t$ in history $S^{t}$ and $h_{i, t+1}\left(S^{t+1}\right)$ is the human wealth of agents of type $i$ at date $t+1$ in history $S^{t+1}$.

Proof. See Appendix A.

V.1. Competitive equilibria. In this section, we find simple expressions for the equations that define an equilibrium. We begin by normalizing the variables of our model by the aggregate endowment, $\omega_{t}\left(S^{t}\right)$. Since this is an endowment economy, this variable is our measure of GDP, equal to income; hence we refer to this procedure as normalizing by income.

Let $\mathcal{A}_{t}$ be the index set of all agents alive at date $t$. Using this definition, we aggregate the consumption function, Equation (33) over all agents of type $i$ alive at date $t$, and divide by income to generate the following expression,

$$
\lambda_{i, t}\left(S^{t}\right)=B_{i}\left[\alpha_{i, t}\left(S^{t}\right)+z_{i, t}\left(S^{t}\right)\right] .
$$

The terms

$$
\begin{aligned}
\lambda_{i, t}\left(S^{t}\right)= & \frac{\sum_{j \in \mathcal{A}_{t}} c_{i, t}^{j}\left(S^{t}\right)}{\omega_{t}\left(S^{t}\right)}, \alpha_{i, t}\left(S_{t}\right)=\frac{\sum_{j \in \mathcal{A}_{t}} a_{i, t}^{j}\left(S^{t}\right)}{\omega_{t}\left(S^{t}\right)}, \\
& \text { and } z_{i, t}\left(S^{t}\right)=\frac{\sum_{j \in \mathcal{A}_{t}} h_{i, t}^{j}\left(S^{t}\right)}{\omega_{t}\left(S^{t}\right)}
\end{aligned}
$$

represent consumption, financial wealth, and human wealth of all members of type $i$, expressed as fractions of GDP. We refer to these variables as the consumption share, the asset ratio and the human wealth ratio for type $i$.

Since there are two types of agents, we define

$$
\lambda_{t}\left(S^{t}\right) \equiv \lambda_{1, t}\left(S^{t}\right)
$$

and we refer to $\lambda_{t}\left(S^{t}\right)$ as simply, the consumption share. From the goods market clearing equation, the consumption shares of the two types must sum to unity, which implies that the consumption share of type 2 agents is given by the expression,

$$
\lambda_{2, t}\left(S^{t}\right)=1-\lambda_{t}\left(S^{t}\right)
$$

Similarly, we refer to

$$
\alpha_{t}\left(S^{t}\right) \equiv \alpha_{1, t}\left(S^{t}\right),
$$


as the asset ratio, since from the asset market clearing equation, the financial assets of type 1 agents must equal the financial liabilities of type 2 agents, and

$$
\alpha_{2, t}\left(S^{t}\right)=-\alpha_{t}\left(S^{t}\right)
$$

Corresponding to the definition of $\lambda_{t}\left(S_{t}\right)$ as the share of income consumed by type 1 agents, we will define $\mu$,

$$
\mu=\frac{\omega_{1, t}}{\omega_{t}}, \quad 1-\mu=\frac{\omega_{2, t}}{\omega_{t}},
$$

to be the share of income owned by type 1 agents.

Using these newly defined terms, we have the following definition of a competitive equilibrium.

Definition 1. A competitive equilibrium is a set of sequences for the consumption share, $\left\{\lambda_{t}\left(S^{t}\right)\right\}$, the asset ratio $\left\{\alpha_{t}\left(S^{t}\right)\right\}$, and the human wealth ratios $\left\{z_{1, t}\left(S^{t}\right)\right\}$ and $\left\{z_{t}\left(S^{t}\right)\right\}$ and a sequence of Arrow security prices $\left\{Q_{t}^{t+1}\left(S^{t+1}\right)\right\}$ such that each household of each generation maximizes expected utility, taking their budget constraint and the sequence of Arrow security prices as given and the goods and asset markets clear. An equilibrium is admissible if $\left\{\lambda_{t}\left(S^{t}\right)\right\} \in(0,1)$ for all $S^{t}$.

In the remainder of the paper, we drop the explicit dependence of $\lambda_{t}, \alpha_{t}, \omega_{t}, c_{t}, c_{1, t}$ and $Q_{t}$ on $S^{t}$ to make the notation more readable.

V.2. Equilibria with intrinsic uncertainty. In their paper, 'Do Sunspots Matter?' Cass and Shell (1983) distinguish between intrinsic uncertainty and extrinsic uncertainty. Intrinsic uncertainty in our model is captured by endowment fluctuations. In this section, we study the case where this is the only kind of uncertainty to influence the economy. Before characterizing equilibrium sequences, we prove the following lemma.

Lemma 1. Let $z_{a}=1 / B_{2}$ and $z_{b}=1 / B_{1}$ and recall that $B_{2}>B_{1}$. There exists an increasing affine function $\zeta: \hat{Z} \equiv\left[z_{a}, z_{b}\right] \rightarrow[0,1]$ such that for all values of the aggregate human wealth ratio, $z \in \hat{Z}$ the equilibrium consumption share $\lambda \in[0,1]$ is given by the expression

$$
\lambda=\zeta(z) \equiv \frac{B_{1} B_{2}}{B_{2}-B_{1}}\left(z-\frac{1}{B_{2}}\right) .
$$

Define the real number

$$
\theta_{0}=B_{1}\left(B_{2}-B_{1}\right)
$$


Then, in a competitive equilibrium, the aggregate human wealth ratio $z_{t}$, the human wealth ratio of type $1, z_{1, t}$ and the asset share $\alpha_{t}$, are related by the affine function,

$$
\theta_{0} z_{1, t}-B_{1} B_{2} z_{t}+\theta_{0} \alpha_{t}+B_{1}=0 .
$$

Proof. See Appendix B.

Using Lemma 1, we establish the following Proposition which characterizes the fundamental equilibrium.

Proposition 2. Define the real numbers,

$$
\begin{aligned}
& \theta_{1}=B_{2}-\pi\left(1-B_{1}\right)+\mu(1-\pi)\left(B_{1}-B_{2}\right), \\
& \theta_{2}=-B_{2}(1-\pi)-\pi B_{1} B_{2}<0, \\
& \theta_{3}=\left(B_{2}-B_{1}\right)(1-\pi)>0, \\
& \theta_{4}=B_{2}-\pi\left(1-B_{1}\right)=\theta_{1}+\mu \theta_{3} .
\end{aligned}
$$

In the case when all uncertainty is intrinsic, the following pair of non-stochastic difference equations describes the evolution of the human wealth ratio of type $1, z_{1, t}$, and of the human wealth ratio, $z_{t}$, in a competitive equilibrium,

$$
\begin{aligned}
z_{1, t+1} & =\frac{\mu-z_{1, t}}{\theta_{1}+\theta_{2} z_{t}+\theta_{3} z_{1, t}}, \\
z_{t+1} & =\frac{1-z_{t}}{\theta_{1}+\theta_{2} z_{t}+\theta_{3} z_{1, t}} .
\end{aligned}
$$

In period $0, z_{1,0}, z_{0}$ and the initial asset ratio $\alpha_{0}$ are linked by the initial condition,

$$
\theta_{0} z_{1,0}-B_{1} B_{2} z_{0}+\theta_{0} \alpha_{0}+B_{1}=0
$$

where

$$
z_{0}=\bar{z}_{0}
$$

The normalized pricing kernel is related to $z_{t}$ and $z_{1, t}$ by the expression

$$
\tilde{Q}_{t}^{t+1}=\frac{-1}{\pi}\left(\frac{\theta_{4}+\theta_{2} z_{t}}{1+\theta_{3} z_{1, t+1}}\right) .
$$

The consumption share $\lambda_{t}$ and the asset ratio $\alpha_{t}$ are given by equations (50) and (51),

$$
\begin{gathered}
\lambda_{t}=\frac{B_{1} B_{2}}{B_{2}-B_{1}}\left(z_{t}-\frac{1}{B_{2}}\right), \\
\alpha_{t}=-\frac{B_{1}}{\theta_{0}}+\frac{\left(B_{1} B_{2} z_{t}-\theta_{0} z_{1, t}\right)}{\theta_{0}} .
\end{gathered}
$$

Proof. See Appendix C. 
Equations (45) and (46) constitute a two-dimensional system in two variables with a single initial condition, represented by Equation (47). These equations are nonstochastic, even when the economy is hit by fundamental shocks, because we have normalized $z_{t}, z_{1, t}$ and $\tilde{Q}_{t}^{t+1}$ by the random endowment. Although $h_{t}$ and $h_{1, t}$ fluctuate in response to random shocks, $z_{t}$ and $z_{1, t}$ do not.

Removing the time subscripts from equations (45) and (46) we define a steady state equilibrium to be a solution to the equations

$$
\begin{aligned}
z_{1}\left(\theta_{1}+\theta_{2} z+\theta_{3} z_{1}\right) & =\mu-z_{1} \\
z\left(\theta_{1}+\theta_{2} z+\theta_{3} z_{1}\right) & =1-z .
\end{aligned}
$$

The following proposition characterizes the properties of a steady state equilibrium and finds two equivalent representations of an equilibrium sequence; one using $z_{t}$ as a state variable and one using $\tilde{Q}_{t}^{t+1}$.

Proposition 3. Equations (52) and (53) have a unique admissible steady state equilibrium, $\left\{z^{*}, z_{1}^{*}\right\}$ such that $z^{*} \in\left(z_{a}, z_{b}\right)$ and $z_{1}^{*}=\mu z^{*}$. The Jacobian of the system (45) and (46), evaluated at $\left\{z^{*}, \mu z^{*}\right\}$, has two real roots, one less than 1 in absolute value and one greater than 1 . It follows that $\left\{z^{*}, \mu z^{*}\right\}$ is a saddle. The stable branch of this saddle is described by a set $\hat{Z} \equiv\left[z_{a}, z_{b}\right], z_{1, t}=\mu z_{t}$ for any $t \geq 0$ and a function $g(\cdot): \hat{Z} \rightarrow \hat{Z}$ such that the first order difference equation

$$
z_{t+1}=g\left(z_{t}\right)
$$

where

$$
g\left(z_{t}\right) \equiv \frac{1-z_{t}}{\theta_{1}+\left(\theta_{2}+\mu \theta_{3}\right) z_{t}}
$$

defines a competitive equilibrium sequence for $\left\{z_{t+1}\right\}$. For all initial values of $z_{0}$ and $z_{1,0}$ where

$$
\begin{gathered}
z_{0} \in \hat{Z}, \\
z_{1,0}=\mu z_{0},
\end{gathered}
$$

$z_{t}$ converges to $z^{*}$. There is an equivalent representation of equilibrium as a difference equation in $\tilde{Q}$. In this representation there exists a set $\hat{Q}=\left[q_{a}, q_{b}\right]$ and a function $h(\cdot): \hat{Q} \rightarrow \hat{Q}$, such that any sequence $\left\{\tilde{Q}_{t}^{t+1}\right\}$ generated by the difference equation

$$
\tilde{Q}_{t+1}^{t+2}=h\left(\tilde{Q}_{t}^{t+1}\right), \quad Q_{0}^{1} \in \hat{Q}
$$

is a competitive equilibrium sequence. The set $\hat{Q}$ and the function $h(\cdot)$ are defined by equations (58) and (59),

$$
q_{a}=-\frac{\theta_{1}+\left(\theta_{2}+\mu \theta_{3}\right) z_{a}}{\pi}, \quad q_{b}=-\frac{\theta_{1}+\left(\theta_{2}+\mu \theta_{3}\right) z_{b}}{\pi},
$$




$$
h\left(\tilde{Q}_{t}^{t+1}\right) \equiv \frac{1-\theta_{1}}{\pi}-\frac{\left(1-B_{1}\right)\left(1-B_{2}\right)}{\pi \tilde{Q}_{t}^{t+1}} .
$$

Every sequence generated by Equation (57), converges to the steady state $\tilde{Q}^{*}$, where $\tilde{Q}^{*}$ is defined in Equation (60),

$$
\tilde{Q}^{*} \equiv-\frac{\theta_{1}+\left(\theta_{2}+\mu \theta_{3}\right) z^{*}}{\pi}=\frac{1-\theta_{1}+\sqrt{\left(1+\theta_{1}\right)^{2}+4\left(\theta_{2}+\mu \theta_{3}\right)}}{2 \pi} .
$$

Proof. See Appendix D.

Proposition 3 implies that the two-dimensional dynamical system in $\left\{z_{t}, z_{1, t}\right\}$ can be reduced to a one-dimensional difference equation, represented by Equation (55), which describes the dynamics of the system on the saddle path.

In Figure 1 we have plotted $z_{t+1}-z_{t}$ on the vertical axis and $z_{t}$ on the horizontal axis. This figure illustrates the dynamics of $z_{t}$, the human wealth ratio, for a parameterized example. To construct this figure, we set the survival probability to 0.98 , which implies that the expected lifetime, conditional on being alive today, is 50 years. The discount factor of type 1 agents is 0.98 , the discount factor of type 2 agents is 0.9 and there are equal shares of each type in the population. 


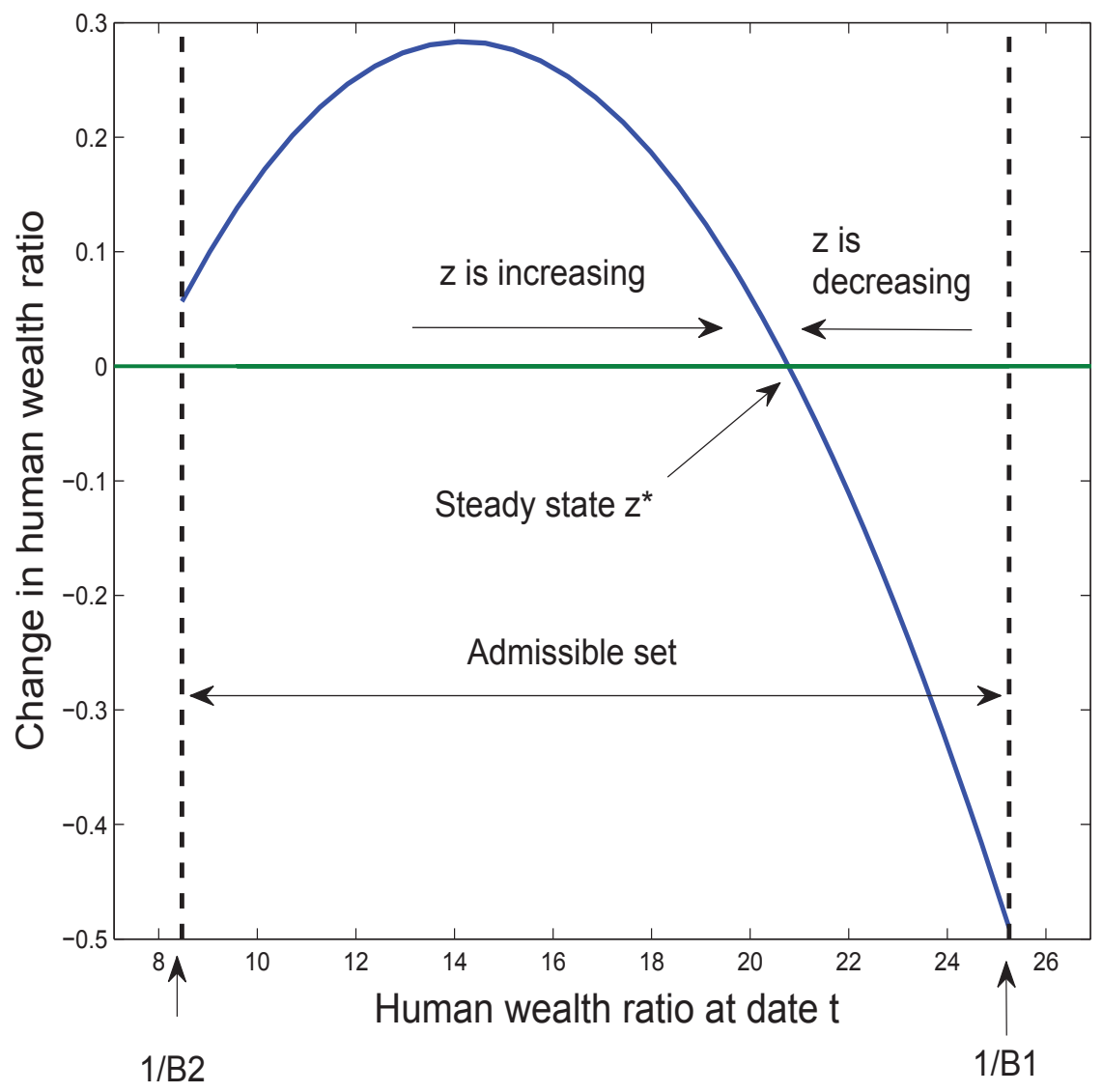

Figure 1: The dynamics of the human wealth equation

V.3. Equilibria with extrinsic uncertainty. Although we assume that agents are able to trade a complete set of Arrow securities, that assumption does not insulate the economy from extrinsic uncertainty. In our model, the human wealth ratio $z_{t}$ and the normalized pricing kernel $\tilde{Q}_{t}^{t+1}$ can fluctuate simply as a consequence of self-fulfilling beliefs. That idea is formalized in the following proposition.

Proposition 4. Let $\varepsilon_{s, t}$ be a sunspot random variable with support $\epsilon \equiv\left[\varepsilon_{a}, \varepsilon_{b}\right]$ where

$$
\begin{gathered}
\varepsilon_{a}=\frac{-\left[\theta_{4}\left(1-\mu \theta_{3}\right)+2 \theta_{2}\right]+\sqrt{\left[\theta_{4}\left(1-\mu \theta_{3}\right)+2 \theta_{2}\right]^{2}-\theta_{4}^{2}\left(1+\mu \theta_{3}\right)^{2}}}{\left(1+\mu \theta_{3}\right)^{2}}, \\
\varepsilon_{b}=\frac{z_{b}\left(\theta_{4}+\theta_{2} z_{b}\right)}{\left(1-z_{b}\right)\left(1+\mu \theta_{3} z_{b}\right)},
\end{gathered}
$$

and $E_{t}\left[\varepsilon_{s, t+1}\right]=1$. Then there exist a set $Z \equiv\left[z_{a}^{\prime}, z_{b}\right]$, a function $g(\cdot): \epsilon \times Z \rightarrow Z$ and a stochastic process defined by the equation

$$
z_{t+1}=g\left(z_{t}, \varepsilon_{s, t+1}\right),
$$


where

$$
g\left(z_{t}, \varepsilon_{s, t+1}\right) \equiv \frac{\left(1-z_{t}\right) \varepsilon_{s, t+1}}{\left(\theta_{4}-\mu \theta_{3} \varepsilon_{s, t+1}\right)+\left(\theta_{2}+\mu \theta_{3} \varepsilon_{s, t+1}\right) z_{t}}
$$

such that any sequence $\left\{z_{t}\right\}$ generated by (64) for $z_{0} \in Z$, is a competitive equilibrium sequence. Further, there is an equivalent representation of equilibrium as the solution to a stochastic difference equation in $\tilde{Q}$. In this representation, there exists a function $h\left(Q, \varepsilon^{\prime}, \varepsilon\right)$, such that

$$
\tilde{Q}_{t}^{t+1}=h\left(\tilde{Q}_{t-1}^{t}, \varepsilon_{s, t+1}, \varepsilon_{s, t}\right)
$$

where,

$$
\begin{gathered}
h\left(\tilde{Q}_{t-1}^{t}, \varepsilon_{s, t+1}, \varepsilon_{s, t}\right) \equiv a\left(\varepsilon_{s, t}, \varepsilon_{s, t+1}\right)+\frac{b\left(\varepsilon_{s, t}, \varepsilon_{s, t+1}\right)}{\tilde{Q}_{t-1}^{t}}, \\
a\left(\varepsilon_{s, t}, \varepsilon_{s, t+1}\right) \equiv \frac{1}{\pi}\left\{\frac{\varepsilon_{s, t}\left(\theta_{2}+\mu \theta_{3} \varepsilon_{s, t+1}\right)}{\left(\theta_{2}+\mu \theta_{3} \varepsilon_{s, t}\right)}-\theta_{4}+\mu \theta_{3} \varepsilon_{s, t+1}\right\},
\end{gathered}
$$

and

$$
b\left(\varepsilon_{s, t}, \varepsilon_{s, t+1}\right) \equiv \frac{1}{\pi^{2}}\left\{\frac{\varepsilon_{s, t}\left(\theta_{2}+\theta_{4}\right)\left(\theta_{2}+\mu \theta_{3} \varepsilon_{s, t+1}\right)}{\left(\theta_{2}+\mu \theta_{3} \varepsilon_{s, t}\right)}\right\} .
$$

The sequence $\left\{\tilde{Q}_{t}^{t+1}\right\}$, generated by a solution to Equation (65), is a competitive equilibrium sequence for $\tilde{Q}$.

Proof. See Appendix E.

Figure 2 illustrates the method used to construct sunspot equilibria. The solid curve represents the function $g(z, 1)$ and the upper and lower dashed curves represent the functions $g\left(z, \varepsilon_{b}\right)$ and $g\left(z, \varepsilon_{a}\right)$. We have exaggerated the curvature of the function $g(\cdot)$ by choosing a value $\beta_{1}=0.98$ and $\beta_{2}=0.3$. The large discrepancy between $\beta_{1}$ and $\beta_{2}$ causes the slopes of these curves to be steeper for low values of $z$ and flatter for high values, thereby making the graph easier to read. 


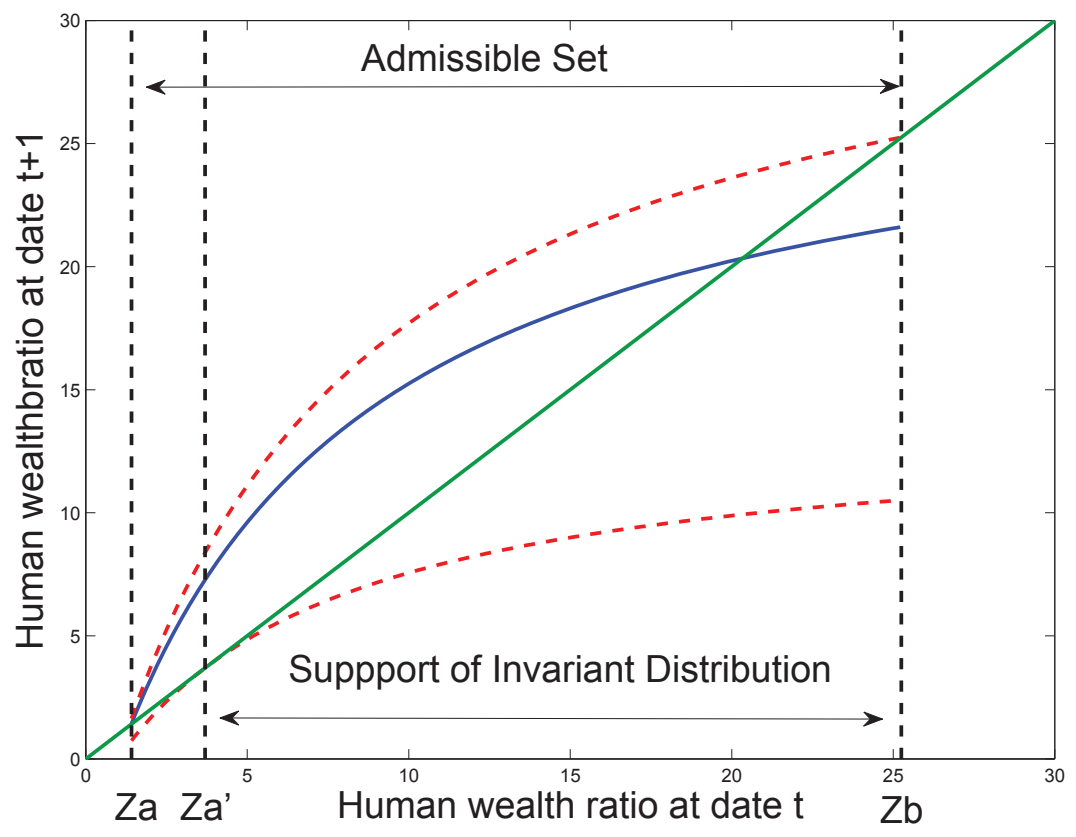

Figure 2: The dynamics of sunspot equilibria

Figure 2 also contrasts the admissible set $\hat{Z} \equiv\left[z_{a}, z_{b}\right]$ with the support of the invariant distribution $Z \equiv\left[z_{a}^{\prime}, z_{b}\right]$. The three vertical dashed lines represent the values $z_{a}, z_{a}^{\prime}$ and $z_{b}$. The lower bound of the largest possible invariant distribution, $z_{a}^{\prime}$ is defined as the point where $g\left(z, \varepsilon_{a}\right)$ is tangent to the $45^{\circ}$ line. Recall that the admissible set is the set of values of $z$ for which the consumption of both types is non-negative and notice that $z_{a}^{\prime}$ is to the right of $z_{a}$, the lower bound of the admissible set. Figure 2 illustrates that the support of the largest possible invariant distribution is a subset of the admissible set. It follows from the results of Futia (1982) that, as $\varepsilon$ fluctuates in the set $\left[\varepsilon_{a}, \varepsilon_{b}\right], z$ converges to an invariant distribution with support $Z \equiv\left[z_{a}^{\prime}, z_{b}\right]^{4}{ }^{4}$

\section{Simulating the invariant Distribution}

Because we know the exact law of motion for the state we are able to compute the moments of any of the variables of our model that are functions of that state. We are also able to simulate individual sequences of artificial data and compare them with data from the real world. This section carries out that exercise.

To compute moments of the invariant distribution, we used the difference equation (63), to construct an approximation to the transition function

$$
T(x, A),
$$

\footnotetext{
${ }^{4}$ The proof builds on Futia (1982) and is identical to the argument used in Farmer and Woodford (1997) Theorem 3, Page 756.
} 
where $x \equiv\{z, \gamma\}$ is the value of the state at date $t$ and $A$ is a set that represents possible values that $z$ and $\gamma$ might take at date $t+1$. For every value of $A, T(\cdot, A)$ is a measurable function and for every value of $x, T(x, \cdot)$ is a probability measure (Stokey, Lucas, and Prescott, 1989, Chaper 8). If $p(x)$ is the probability that the system is in state $x$ at date $t$ then

$$
p^{\prime}\left(x^{\prime}\right)=\int_{X} T\left(x, x^{\prime}\right) d p(x),
$$

is the probability that it is in state $x^{\prime}$ at date $t+1$. By iterating on this operator equation for arbitrary initial $p$ we arrive at an expression for the invariant measure. This invariant measure, $p(x)$, is the unconditional probability of observing the system in state $x=\{z, \gamma\}$.

In a technical appendix to this paper, available from the authors, we explain how to compute a discrete Markov chain approximation to Equation (70). The simulation results reported in figures 3 and 4 were computed using this discrete approximation. In addition to the four parameters, $\pi, \beta_{1}, \beta_{2}$ and $\mu$, which we set to

$$
\pi=0.98, \quad \beta_{1}=0.98, \quad \beta_{2}=0.9, \quad \mu=0.5
$$

as in the earlier part of the paper, we calibrated three additional parameters. We assumed that endowment growth is a geometric random walk with mean 1 and variance $\sigma_{f}^{2}$ and that $\exp \left(\varepsilon_{s}\right)$ is normal with mean 1 and variance $\sigma_{s}^{2}$. In our baseline calibration we set the correlation coefficient $\rho$ between $\varepsilon_{s}$ and $\varepsilon_{f}$ equal to zero. We also experimented with values of $\rho$ from -0.99 to +0.99 with little effect on the results. The calibrated values of $\sigma_{s}, \sigma_{f}$ and $\rho$ were set to

$$
\sigma_{f}=0.015, \quad \sigma_{s}=0.035, \quad \rho=0 \text {. }
$$

The choice of $\sigma_{f}$ was set to equal the standard deviation of consumption growth in post war U.S. data and the standard deviation of $\varepsilon_{s}$ was set to the largest value that was consistent with minimal truncation bias. ${ }^{5}$ Figure 3 depicts the invariant distribution $p(x)$ for these parameter values.

\footnotetext{
${ }^{5}$ Larger values of $\sigma_{s}$ cause the invariant distribution piling up at the end points as a consequence of truncation bias.
} 


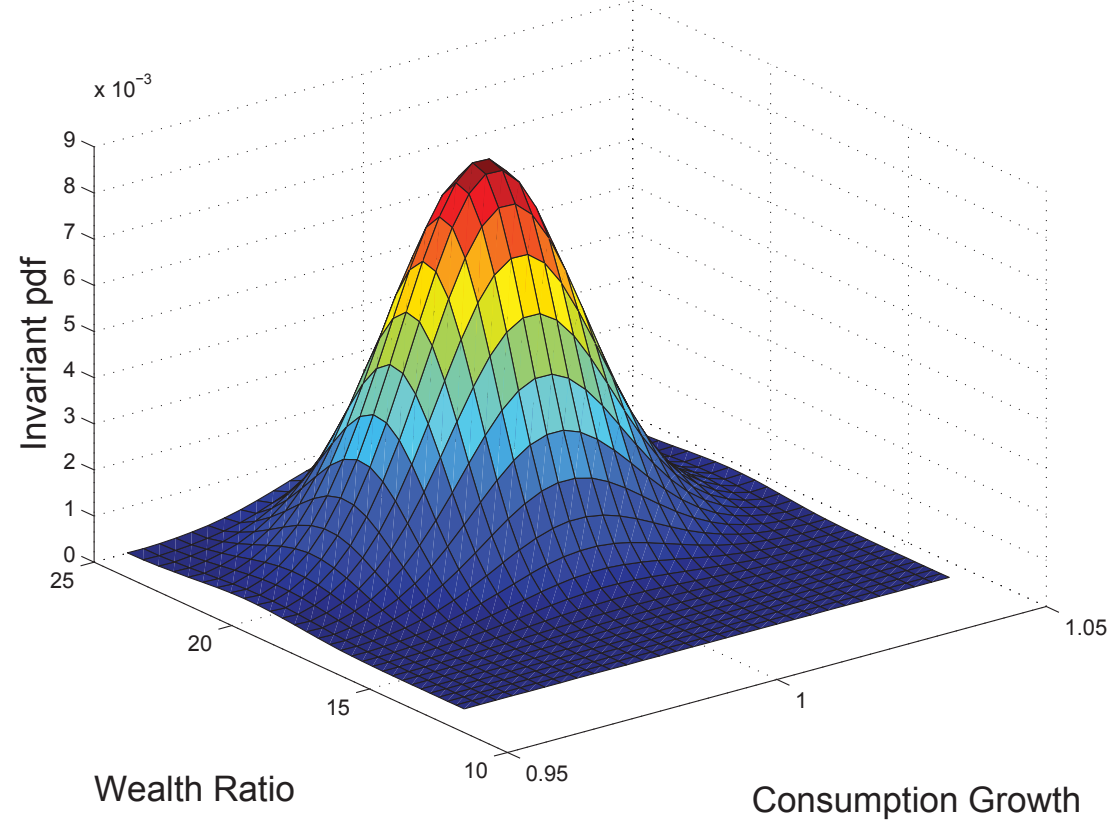

Figure 3: The joint invariant distribution of consumption growth and the human wealth ratio

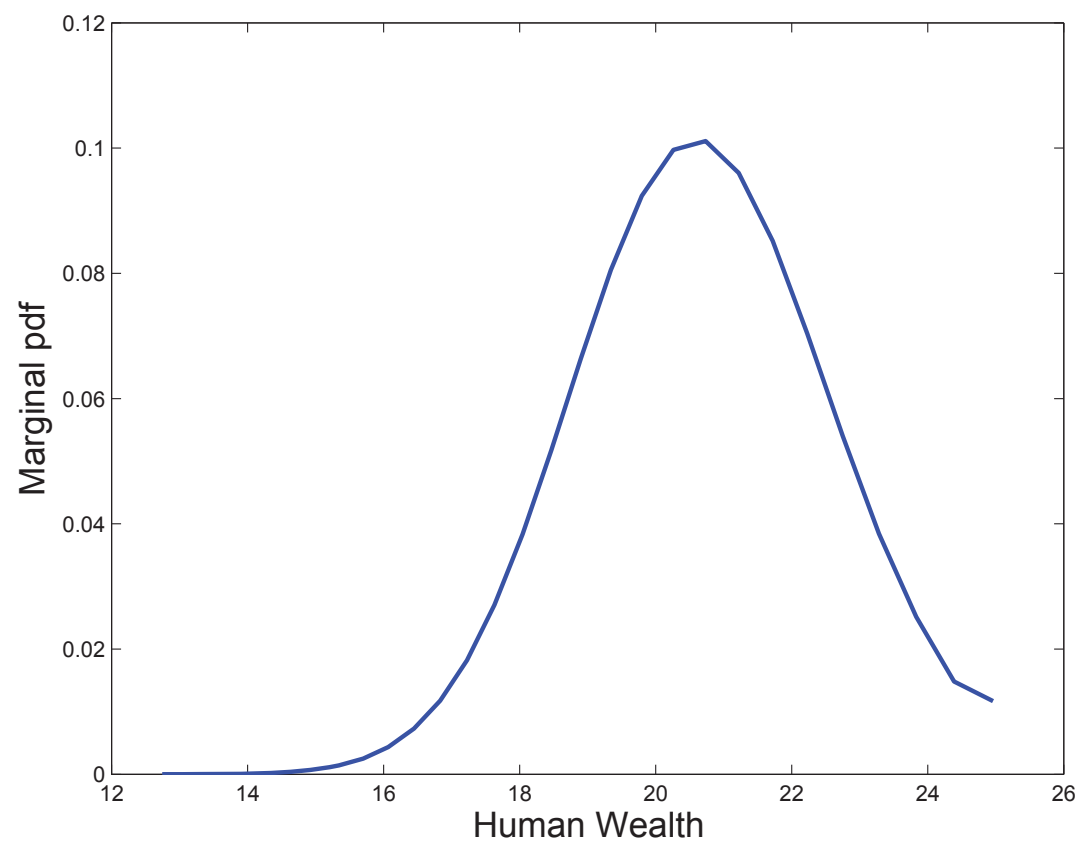

Figure 4: The marginal invariant distribution of the human wealth ratio

In Figure 4 we report the marginal distribution over the human wealth ratio. The median human wealth ratio is a little over 20 , but there is considerable probability mass that this ratio will be less than 18 or greater than 23 . That difference represents 
twenty five percent of the median human wealth. If we define a recession to be a value of the human wealth ratio less than 18 and a boom, a ratio greater than 23, then a person of either type who is born into a recession will have lifetime wealth that is approximately twenty five percent lower than a similar person born in a boom. These are big numbers.

VI.1. The features of simulated data series. To give some idea of the time series properties of data generated by our model, we simulated a single draw of 60 years of data using the parameters reported above. Figure 5 reports the results of that exercise.
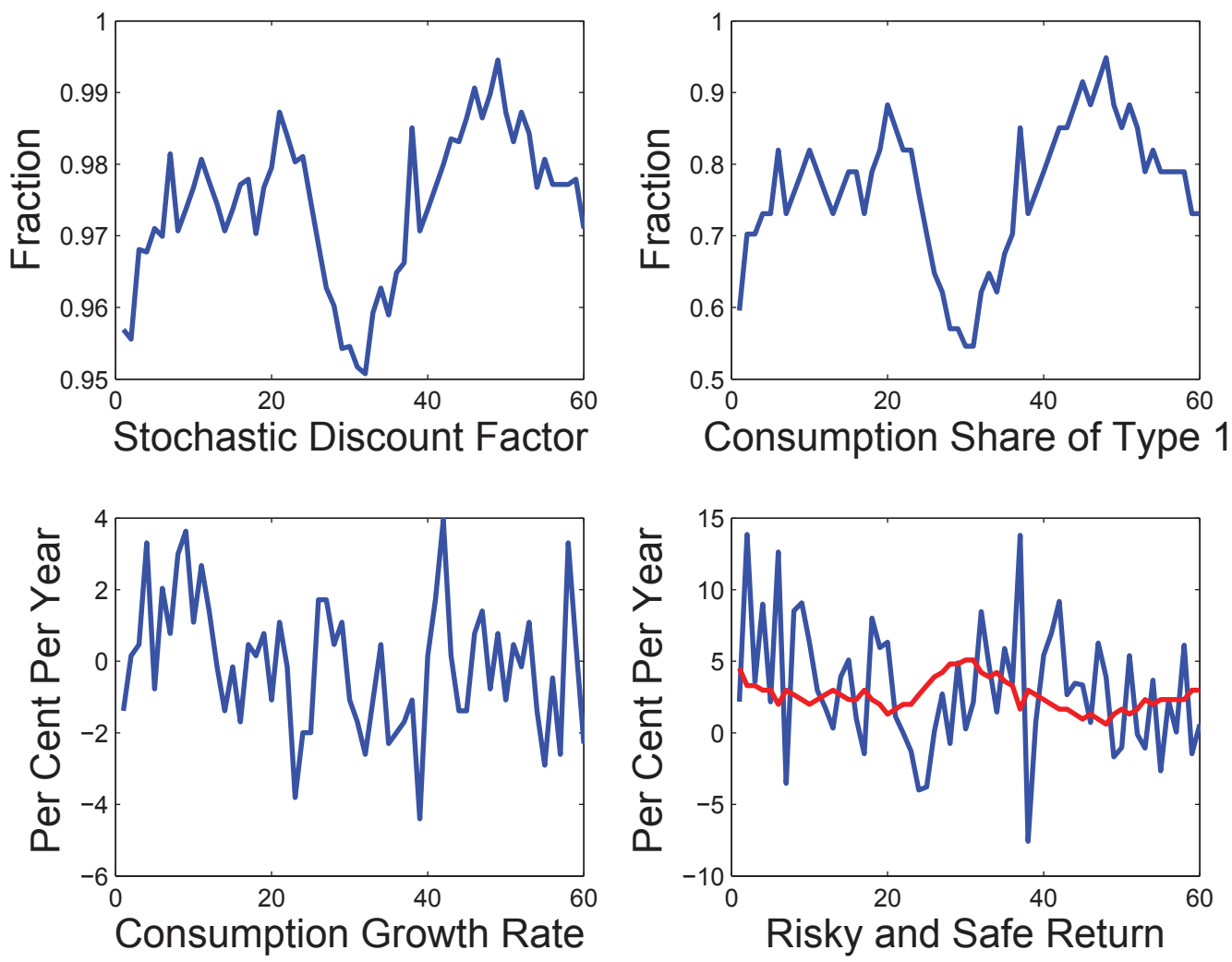

Figure 5: Four time series generated by simulating sixty years of data

The top left panel of Figure 5 shows the stochastic discount factor and the top right is the consumption share of type 1 agents. Notice that this share varies considerably over the sample with consumption as low as 0.6 and as high as $0.9 .^{6}$ But although

\footnotetext{
${ }^{6}$ Although this volatility may seem large, there is evidence that high income individuals who own stock have consumption growth that is four times as volatile as average consumption growth (Malloy, Moskowitz, and Vissing-Jorgensen, 2009).
} 
the consumption fraction of type 1 agents is volatile, aggregate consumption growth, shown in the bottom left panel, matches the volatility found in U.S. data. The standard deviation of aggregate consumption growth in the invariant distribution is equal to 0.015 , the same as in the post-war U.S. The bottom right panel shows that the mean equity return is much more volatile than the safe return which is relatively smooth, just as we find in U.S. data.

The returns to debt and equity in our model were computed as follows. Since our model does not contain capital, a claim to equity is the same thing as a claim to the endowment stream of a living agent. Let

$$
q_{t} \equiv h_{t},
$$

be the price of a 'cum-dividend' traded claim to the endowment stream. We can express the return to this claim as

$$
R^{R}\left(S^{t+1}\right)=\frac{\pi q\left(S^{t+1}\right)}{q\left(S^{t}\right)-\omega_{t}} \equiv\left(\frac{\pi z\left(S^{t+1}\right)}{z\left(S^{t}\right)-1}\right) \gamma\left(S^{t+1}\right)
$$

where the $\pi$ in the numerator of this expression represents the fact that the claim has a probability $\pi$ of being repaid. We can also price a safe claim to a unit of the consumption good,

$$
p^{b}\left(S^{t}\right)=\sum_{s_{t}} Q_{t}^{t+1}\left(S^{t+1}\right)
$$

which offers a risk free gross return of,

$$
R^{S}\left(S^{t+1}\right)=\frac{1}{p^{b}\left(S^{t}\right)}
$$

Using these definitions we found that when $z$ and $\gamma$ are uncorrelated, the Sharpe ratio in the invariant distribution is 0.007. By increasing the correlation to 0.9, it is possible to increase this to 0.02. While this is a factor of ten larger than the representative agent model when preferences are logarithmic, it is still a factor of ten too small compared with time series data. Although we are able to explain the volatility of the pricing kernel, our model does not help us to explain the equity premium.

\section{Conclusion}

The first welfare theorem of general equilibrium theory asserts that every competitive equilibrium is Pareto optimal. When financial markets are complete, and when all agents are able to participate in financial markets, this theorem implies that unrestricted trade in financial assets will lead to the efficient allocation of risk to those who are best able to bear it. 
We have shown, in this paper, that competitive financial markets do not lead to Pareto efficient outcomes and that the failure of complete financial markets to deliver socially efficient allocations has nothing to do with frictions, market incompleteness or transactions costs of any kind. The first welfare theorem fails because participation in financial markets is necessarily incomplete as a consequence of the fact that agents cannot trade risk in financial markets that open before they are born. For this reason, financial markets do not work well in our model and we conjecture that for the same reason, they do not work well in the real world.

The Ramsey-Cass-Koopmans model (Ramsey, 1928; Koopmans, 1965; Cass, 1965) underpins not only all of modern macroeconomics, but also all of modern finance theory. Existing literature modifies this model by adding frictions of one kind or another to explain why free trade in competitive markets cannot achieve an efficient allocation of risk. It has not, as yet, offered a convincing explanation for the volatility of the stochastic discount factor in real world data. Although our work is close to the Ramsey-Cass-Koopmans model, we do not need to assume frictions of any kind. In our model, financial markets are not Pareto efficient, except by chance. Although individuals in our model are rational; markets are not.

\section{APPENDIX}

\section{Appendix A.}

Proof of Proposition 1. If we sum Equation (29) over all agents of type $i$ who were alive at date $t$, we arrive at the equation,

$$
Q_{t}^{t+1}\left(S^{t+1}\right)=\frac{\psi\left(S^{t+1}\right) \beta_{i} \sum_{j \in \mathcal{A}_{t}} c_{i, t}^{j}\left(S^{t}\right)}{\sum_{j \in \mathcal{A}_{t}} c_{i, t+1}^{j}\left(S^{t+1}\right)}
$$

The consumption at date $t+1$ of everyone of type $i$ who was alive at date $t$, is equal to the consumption of all agents of type $i$ minus the consumption of the new borns. For any date $t+1$ and any variable $x$ let $x_{t}^{j}$ be the quantity of that variable held by a household of generation $j$ and let $X_{t}$ be the aggregate quantity. Let $\mathcal{A}_{t}$ be the index set of all agents alive at date $t$ and let $\mathcal{N}_{t+1}$ denote the set of newborns at period $t+1$. Then,

$$
\pi \sum_{j \in \mathcal{A}_{t}} x_{t+1}^{j}+\sum_{j \in \mathcal{N}_{t+1}} x_{t+1}^{j}=\sum_{j \in \mathcal{A}_{t+1}} x_{t+1}^{j}=X_{t+1} .
$$

Using Equation (A.2) we can write the denominator of Equation (A.1) as,

$$
\sum_{j \in \mathcal{A}_{t}} c_{i, t+1}^{j}\left(S^{t+1}\right)=\frac{1}{\pi}\left(\sum_{j \in \mathcal{A}_{t+1}} c_{i, t+1}^{j}\left(S^{t+1}\right)-\sum_{j \in \mathcal{N}_{t+1}} c_{i, t+1}^{j}\left(S^{t+1}\right)\right) .
$$


The first term on the right-hand-side of this equation is aggregate consumption of type $i$, which we define as

$$
C_{i, t+1}\left(S^{t+1}\right) \equiv \sum_{j \in \mathcal{A}_{t+1}} c_{i, t+1}^{j}\left(S^{t+1}\right)
$$

The second term is the consumption of the newborns of type $i$. Because these agents are born with no financial assets, their consumption is proportional to their human wealth. This leads to the expression

$$
\sum_{j \in \mathcal{N}_{t+1}} c_{i, t+1}^{j}\left(S^{t+1}\right)=B_{i}(1-\pi) h_{i, t+1}\left(S^{t+1}\right),
$$

where the coefficient $(1-\pi)$, is the fraction of newborns of type $i$. Using equations (A.3)-(A.5) we can rewrite (A.1) as

$$
Q_{t}^{t+1}\left(S^{t+1}\right)=\frac{\psi\left(S^{t+1}\right)\left(1-B_{i}\right) C_{i, t}\left(S^{t}\right)}{C_{i, t+1}\left(S^{t+1}\right)-B_{i}(1-\pi) h_{i, t+1}\left(S^{t+1}\right)},
$$

which is Equation (34), the expression we seek.

\section{Appendix B.}

Proof of Lemma 1. From Equation(35), evaluated for types 1 and 2, we get

$$
\begin{gathered}
\alpha_{t}=\frac{\lambda_{t}}{B_{1}}-z_{1, t}, \\
-\alpha_{t}=\frac{1-\lambda_{t}}{B_{2}}-z_{2, t} .
\end{gathered}
$$

Summing (B.1) and (B.2) and rearranging leads to Equation (41). The fact that $\zeta$ is increasing in $z$ follows from the assumption, $B_{2}>B_{1}$. The domain of $\zeta$ is found by evaluating $\zeta^{-1}$ for values of $\lambda=0$ and $\lambda=1$.

From (41) we have that,

$$
\lambda_{t}=\frac{B_{1} B_{2}}{B_{2}-B_{1}}\left(z_{t}-\frac{1}{B_{2}}\right),
$$

which expresses the consumption share as a function of the aggregate human wealth ratio. From the consumption function of type 1 agents, Equation (35), we have the following expression linking the consumption share with the asset share, and with the type 1 human wealth ratio,

$$
\lambda_{t}=B_{1}\left(\alpha_{t}+z_{1, t}\right) .
$$

Combing equations (B.3) and (B.4) gives

$$
B_{1}\left(\alpha_{t}+z_{1, t}\right)=\frac{B_{1} B_{2}}{B_{2}-B_{1}}\left(z_{t}-\frac{1}{B_{2}}\right) .
$$

Using definition, (42), this leads to Equation (43), the expression we seek. 


\section{Appendix C.}

Proof of Proposition 2. From Proposition 1 and the restriction to perfect foresight equilibria, we have that

$$
\lambda_{t}=\frac{B_{1} B_{2}}{B_{2}-B_{1}}\left(z_{t}-\frac{1}{B_{2}}\right) .
$$

Leading Equation (C.1) one period gives,

$$
\lambda_{t+1}=\frac{B_{1} B_{2}}{B_{2}-B_{1}}\left(z_{t+1}-\frac{1}{B_{2}}\right) .
$$

Dividing the numerator of Equation (34), by $\omega_{t}$ and dividing the denominator by $\omega_{t+1}$ leads to the following expressions that relate the normalized pricing kernel to the consumption share and to the human wealth ratio of each type,

$$
\begin{gathered}
\tilde{Q}_{t}^{t+1}=\frac{\left(1-B_{1}\right) \lambda_{t}}{\lambda_{t+1}-B_{1}(1-\pi) z_{1, t+1}}, \\
\tilde{Q}_{t}^{t+1}=\frac{\left(1-B_{2}\right)\left(1-\lambda_{t}\right)}{\left(1-\lambda_{t+1}\right)-B_{2}(1-\pi) z_{2, t+1}} .
\end{gathered}
$$

These expressions follow from the fact that agents of each type equate the marginal rate of substitution to the pricing kernel, state by state.

Next, we divide the human wealth equation, (30), by the aggregate endowment. That leads to the following difference equation in the human wealth ratio for type $i$,

$$
z_{i, t}=\mu_{i}+\pi E_{t}\left[\tilde{Q}_{t}^{t+1} z_{i, t+1}\right]
$$

Adding up Equation (C.5) over both types leads to the following expression for the aggregate human wealth ratio,

$$
z_{t}=1+\pi E_{t}\left[\tilde{Q}_{t}^{t+1} z_{t+1}\right] .
$$

From equations (C.3) and (C.4),

$$
\begin{gathered}
\tilde{Q}_{t}^{t+1}=\frac{\left(1-B_{2}\right)\left(1-\lambda_{t}\right)}{1-\lambda_{t+1}-B_{2}(1-\pi) z_{2, t+1}}, \\
\tilde{Q}_{t}^{t+1}=\frac{\left(1-B_{1}\right) \lambda_{t}}{\lambda_{t+1}-B_{1}(1-\pi) z_{1, t+1}} .
\end{gathered}
$$

Substituting for $\lambda_{t}$ and $\lambda_{t+1}$ from equations (C.1) and (C.2) into (C.8), we obtain the following expression for $z_{2, t+1}$ as a function of $z_{t}$ and $z_{1, t}{ }^{7}$

$$
z_{2, t+1}=-\frac{\left(\pi B_{1}-B_{1}-\pi B_{1} B_{2}\right) z_{t} z_{1, t+1}+z_{t}+\left(B_{1}-\pi+\pi B_{2}\right) z_{1, t+1}-1}{\left(\pi B_{2}-B_{2}-\pi B_{1} B_{2}\right) z_{t}+\left(B_{2}+\pi\left(B_{1}-1\right)\right)} .
$$

\footnotetext{
${ }^{7}$ The algebra used to derive (C.9) was checked using Maple in Scientific Workplace. The code is available from the authors on request.
} 
Define the following transformed parameters

$$
\begin{aligned}
& \theta_{1}=B_{2}-\pi\left(1-B_{1}\right)+\mu(1-\pi)\left(B_{1}-B_{2}\right), \\
& \theta_{2}=-B_{2}(1-\pi)-\pi B_{1} B_{2}<0 \\
& \theta_{3}=\left(B_{2}-B_{1}\right)(1-\pi) \\
& \theta_{4}=B_{2}-\pi\left(1-B_{1}\right)=\theta_{1}+\mu \theta_{3} .
\end{aligned}
$$

Combining equation (C.1)-(C.3) with (C.5), using (C.9) and (C.10) gives the following expression for the normalized pricing kernel,

$$
\pi \tilde{Q}_{t}^{t+1}=-\frac{\theta_{1}+\mu \theta_{3}+\theta_{2} z_{t}}{1+\theta_{3} z_{1, t+1}}=-\frac{\theta_{4}+\theta_{2} z_{t}}{1+\theta_{3} z_{1, t+1}} .
$$

Because we have normalized all variables by income, none of the equations of our model contain random variables. Hence we may drop the expectations operator and write the human wealth equations, (C.5) and (C.6) as follows,

$$
\begin{gathered}
z_{1, t}=\mu+\pi \tilde{Q}_{t}^{t+1} z_{1, t+1}, \\
z_{t}=1+\pi \tilde{Q}_{t}^{t+1} z_{t+1} .
\end{gathered}
$$

Rearranging Equations (C.12) and (C.13), replacing $\tilde{Q}_{t}^{t+1}$ from (C.11), gives,

$$
\begin{gathered}
z_{1, t+1}=\frac{\mu-z_{1, t}}{\theta_{1}+\theta_{2} z_{t}+\theta_{3} z_{1, t}}, \\
z_{t+1}=\frac{1-z_{t}}{\theta_{1}+\theta_{2} z_{t}+\theta_{3} z_{1, t}},
\end{gathered}
$$

which are the expressions for equations (45) and (46) that we seek. The initial condition, Equation (47), follows from Proposition 1 and the expression for the normalized pricing kernel.

\section{Appendix D.}

Proof of Proposition 3. Evaluating equations (C.14) and (C.15) at a steady state $\left(z_{1, t}, z_{t}\right)=\left(z_{1}^{*}, z^{*}\right)$, and considering their ratio gives $z_{1}^{*}=\mu z^{*}$. It follows that a steady state equilibrium $z^{*}$ is a solution of the following second degree polynomial

$$
\mathcal{P}(z)=z^{2}\left(\theta_{2}+\mu \theta_{3}\right)+z\left(1+\theta_{1}\right)-1=0 .
$$

Define the discriminant

$$
\Delta=\left(1+\theta_{1}\right)^{2}+4\left(\theta_{2}+\mu \theta_{3}\right) .
$$

Using the fact that $B_{2}>B_{1}$, it follows from the definitions of $\theta_{1}, \theta_{2}$ and $\theta_{3}$ that

$$
\theta_{1}>B_{2}-\pi\left(1-B_{1}\right), \theta_{3}>0
$$

and hence

$$
\theta_{2}+\mu \theta_{3}>\theta_{2}
$$


Using inequalities (D.3) and (D.4) to replace $\left(\theta_{2}+\mu \theta_{3}\right)$ by $\theta_{2}$ and replacing $\theta_{2}$ by its definition, it follows that

$$
\Delta>\left[B_{2}+1-\pi\left(1-B_{1}\right)\right]^{2}-4 B_{2}\left[1-\pi\left(1-B_{1}\right)\right]=\left[B_{2}-1+\pi\left(1-B_{1}\right)\right]^{2} \geq 0 .
$$

Since the discriminant is non-negative, there exist two real solutions to Equation (D.1), $z^{*}$ and $z^{* *}$, given by the expressions,

$$
z^{*}=-\frac{1+\theta_{1}+\sqrt{\Delta}}{2\left(\theta_{2}+\mu \theta_{3}\right)}>z^{* *}=-\frac{1+\theta_{1}-\sqrt{\Delta}}{2\left(\theta_{2}+\mu \theta_{3}\right)} .
$$

We next check that these two solutions belong to the admissible set $\left(z_{a}, z_{b}\right)$. Consider first the lower solution $z^{* *}$. Rearranging the definition of $z^{* *}$ it follows that $z^{* *}>z_{a} \equiv 1 / B_{2}$ if and only if

$$
1+\theta_{1}+\frac{2\left(\theta_{2}+\mu \theta_{3}\right)}{B_{2}}<\sqrt{\Delta}
$$

Squaring both sides of (D.7) and substituting for $\Delta$ from (D.2) implies that, equivalently,

$$
1+\theta_{1}-B_{2}+\frac{\theta_{2}+\mu \theta_{3}}{B_{2}}<0
$$

Substituting the expressions for $\theta_{1}, \theta_{2}$ and $\theta_{3}$ into this inequality and rearranging terms leads to the following expression for the left-hand side of (D.8),

$$
\mu(1-\pi)\left(B_{2}-B_{1}\right) \frac{1-B_{2}}{B_{2}}>0
$$

where the inequality in (D.9) follows since $1>B_{2}>B_{1}>0$ and $\pi<1$. It follows that $z^{* *}<z_{a}$ and hence $z^{* *}$ is not an admissible steady state.

Consider now the larger of the two solutions, $z^{*}$. The same computation as previously allows us to conclude that $z^{*}>z_{a}$. We must next show that $z^{*}<z_{b} \equiv 1 / B_{1}$. Using the definition of $z^{*}$, this occurs if and only if

$$
1+\theta_{1}+\frac{2\left(\theta_{2}+\mu \theta_{3}\right)}{B_{1}}<-\sqrt{\Delta}
$$

A necessary condition for this inequality to hold is that the left-hand side is negative. Using the definitions of $\theta_{1}, \theta_{2}$ and $\theta_{3}$, we may write the left side of (D.10) as the following second degree polynomial in $B_{1}$,

$$
\begin{aligned}
\mathcal{G}\left(B_{1}\right)= & B_{1}\left[1+B_{2}-\pi\left(1-B_{1}\right)+\mu(1-\pi)\left(B_{1}-B_{2}\right)\right] \\
& -2\left[B_{2}(1-\pi)+\pi B_{1} B_{2}+\mu(1-\pi)\left(B_{1}-B_{2}\right)\right] .
\end{aligned}
$$

The left-hand side of (D.10) is then negative when $\mathcal{G}\left(B_{1}\right)<0$. Notice that $\mathcal{G}\left(B_{1}\right)$ is convex with $\mathcal{G}( \pm \infty)=+\infty$. Further, as $\mathcal{G}\left(B_{1}\right)$ is defined over the set $\left(0, B_{2}\right)$, we have that $\mathcal{G}(0)=-2 B_{2}(1-\pi)(1-\mu)<0$ and $\mathcal{G}\left(B_{2}\right)=-B_{2}(1-\pi)\left(1-B_{2}\right)<0$. 
It follows that for any $B_{1} \in\left(0, B_{2}\right), \mathcal{G}\left(B_{1}\right)<0$ and thus the left-hand side of (D.10) is negative. Squaring both sides of (D.10) and substituting for $\Delta$ from (D.2) implies that inequality (D.10) holds if and only if

$$
1+\theta_{1}-B_{1}+\frac{\theta_{2}+\mu \theta_{3}}{B_{1}}<0
$$

Substituting the expressions for $\theta_{1}, \theta_{2}$ and $\theta_{3}$ into this inequality and simplifying the expression yields to the following formulation for the left-hand side of (D.12)

$$
-(1-\pi)(1-\mu)\left(1-B_{1}\right)\left(B_{2}-B_{1}\right)<0 \text {. }
$$

This inequality establishes that $z^{*} \in \hat{Z}$ and hence $z^{*}$ is an admissible steady state. We study the stability properties of $z^{*}$ by linearizing the dynamical system (45)-(46) around $z^{*}$. Using the steady state relationships (52) and (53), we get after some simplification, the following Jacobian matrix

$$
\mathcal{J}=\left(\begin{array}{cc}
\frac{z^{*}-1}{z^{*}}\left(1+\theta_{2} z^{*}\right) & \left(z^{*}-1\right) \theta_{3} \\
\left(z^{*}-1\right) \mu \theta_{2} & \frac{z^{*}-1}{z^{*}}\left(1+\mu \theta_{3} z^{*}\right)
\end{array}\right) .
$$

The associated characteristic polynomial is

$$
\begin{aligned}
& {\left[\frac{z^{*}-1}{z^{*}}\left(1+\theta_{2} z^{*}\right)-x\right] } {\left[\frac{z^{*}-1}{z^{*}}\left(1+\mu \theta_{3} z^{*}\right)-x\right]-\left(z^{*}-1\right)^{2} \mu \theta_{2} \theta_{3}, } \\
&=\left(x-\frac{z^{*}}{z^{*}-1}\right)\left(x-\frac{1-\theta_{1} z^{*}}{z^{*}-1}\right)=0
\end{aligned}
$$

with characteristic roots

$$
\begin{gathered}
x_{1}=\frac{z^{*}}{z^{*}-1}>1, \\
x_{2}=\frac{1-\theta_{1} z^{*}}{z^{*}-1} .
\end{gathered}
$$

We next establish that this steady state is a saddle and that the dynamical system (45)-(46) is globally stable. Since, from (D.16a), $x_{1}$ is positive and greater than one, we need only establish a general property to guarantee global conclusion and that $-1<x_{2}<1$. Let us first consider the derivative of $g(z)$ for any $z, g^{\prime}(z)=$ $\left(1-\theta_{1} z\right) /(z-1)$. Since $z>1$, we have $g^{\prime}(z) \geq-1$ for any $z \in\left(z_{a}, z_{b}\right)$ if $1-\theta_{1} \geq 0$, which holds since $B_{2}>B_{1}$. This property implies that $x_{2}>-1$. Moreover, we get $g^{\prime}\left(z_{a}\right)>0$ if and only if $B_{2}-\theta_{1}>0$, which again holds as $B_{2}>B_{1}$. We then establish that $x_{2}<1$. From (D.16b), this follows if and only if $2-\left(1+\theta_{1}\right) z^{*}<0$. Equivalently using the definitions of $\theta_{1}$ and $z^{*}$, together with the fact that $\theta_{2}+\mu \theta_{3}<0, x_{2}<1$, if 
and only if

$$
\begin{aligned}
4\left(\theta_{2}+\mu \theta_{3}\right)+\left(1+\theta_{1}\right)\left[1+\theta_{1}+\sqrt{\Delta}\right] & =\Delta+\left(1+\theta_{1}\right) \sqrt{\Delta} \\
& =\sqrt{\Delta}\left[1+\theta_{1}+\sqrt{\Delta}\right]>0 .
\end{aligned}
$$

We derive from (C.10) that

$$
1+\theta_{1}=B_{2}[1-\mu(1-\pi)]+B_{1} \mu(1-\pi)+1-\pi\left(1-B_{1}\right)>0
$$

and thus $x_{2}<1$. Since $x_{1}>1$ we conclude that $z^{*}$ is saddle-point stable. It follows that the equilibrium must be unique and given by the stable branch of the saddlepoint since any other path will violate the feasibility conditions. Consider then the ratio of equations (C.14) and (C.15). We get:

$$
\frac{z_{1, t+1}}{z_{t+1}}=\frac{\mu-z_{1, t}}{1-z_{t}}
$$

Obviously, this ratio admits $z_{1, t}=\mu z_{t}$ for all $t$ as a solution. Uniqueness of the equilibrium implies that this solution is the unique equilibrium of the dynamical system (C.14)-(C.15) in $\left(z_{t}, z_{1, t}\right)$ which can then be reduced to the one-dimensional difference equation defined by Equation (55). Further, $z^{*}$ is globally stable for any $z_{t} \in \hat{Z}$.

Next we turn to an equivalent representation of the system using $\tilde{Q}_{t}^{t+1}$ as a state variable. Replacing $z_{1, t+1}$ from (45) in Equation (49), and simplifying the resulting expression gives,

$$
\tilde{Q}_{t}^{t+1}=-\frac{\theta_{1}+\theta_{2} z_{t}+\theta_{3} z_{1, t}}{\pi} .
$$

Substituting the restriction $z_{1, t}=\mu z_{t}$ into Equation (D.20) and inverting the equation to find $z_{t}$ as a function of $\tilde{Q}_{t}^{t+1}$, leads to

$$
z_{t}=-\frac{\pi \tilde{Q}_{t}^{t+1}+\theta_{1}}{\theta_{2}+\mu \theta_{3}}
$$

Substituting this expression into (55) and rearranging terms leads to the difference equation

$$
\tilde{Q}_{t+1}^{t+2}=h\left(\tilde{Q}_{t}^{t+1}\right)
$$

where

$$
h\left(\tilde{Q}_{t}^{t+1}\right) \equiv \frac{1-\theta_{1}}{\pi}+\frac{\theta_{1}+\theta_{2}+\mu \theta_{3}}{\pi^{2} \tilde{Q}_{t}^{t+1}}=\frac{1-\theta_{1}}{\pi}-\frac{\left(1-B_{1}\right)\left(1-B_{2}\right)}{\pi \tilde{Q}_{t}^{t+1}},
$$

which provides an equivalent representation of the equilibrium in terms of $\tilde{Q}$. Using the same arguments as previously, it follows that for all $Q_{0}^{1} \in\left(q_{a}, q_{b}\right)$ with

$$
q_{a}=-\frac{\theta_{1}+\left(\theta_{2}+\mu \theta_{3}\right) z_{a}}{\pi}, \quad q_{b}=-\frac{\theta_{1}+\left(\theta_{2}+\mu \theta_{3}\right) z_{b}}{\pi},
$$


there exists a sequence of equilibrium asset prices described by the difference equation (D.22), that converges to the steady state pricing kernel.

\section{Appendix E.}

Proof of Proposition 4. Consider the definition of human wealth,

$$
z_{t}=1+E_{t}\left[\pi \tilde{Q}_{t}^{t+1} z_{t+1}\right]
$$

In Proposition 2, Equation (C.11), we derived an expression for the pricing kernel $\tilde{Q}_{t}^{t+1}\left(z_{t}, z_{1, t+1}\right)$, that we write below as Equation (E.2).

$$
\pi \tilde{Q}_{t}^{t+1}=-\left(\frac{\theta_{4}+\theta_{2} z_{t}}{1+\theta_{3} z_{1, t+1}}\right) .
$$

Replacing (E.2) in (E.1), and restricting attention to the stable branch of the saddle by setting $z_{1, t}=\mu z_{t}$, we arrive at the following functional equation,

$$
z_{t}=1+E_{t}\left[-\left(\frac{\theta_{4}+\theta_{2} z_{t}}{1+\mu \theta_{3} z_{t+1}}\right) z_{t+1}\right] .
$$

Since Equation (E.3) characterizes equilibria, it follows that any admissible sequence $\left\{z_{t}\right\}$ that satisfies Equation (E.3) is an equilibrium sequence. We now show how to construct a stochastic process for $\left\{z_{t}\right\}$ that generates admissible solutions to (E.3). Let $\varepsilon_{s, t+1}$, be a bounded, i.i.d. random variable with support $\epsilon \equiv\left[\varepsilon_{a}, \varepsilon_{b}\right]$ such that

$$
E_{t}\left(\varepsilon_{s, t+1}\right)=1
$$

and consider sequences for $\left\{z_{t}\right\}, z \in Z \equiv\left(z_{a}^{\prime}, z_{b}\right)$ that satisfy the equation,

$$
\left(z_{t}-1\right) \varepsilon_{s, t+1}=-\left(\frac{\theta_{4}+\theta_{2} z_{t}}{1+\theta_{3} \mu z_{t+1}}\right) z_{t+1} .
$$

Rearranging (E.5), using the fact that $\theta_{4}-\mu \theta_{3}=\theta_{1}$, we may define a function $g(\cdot): Z \times \epsilon \rightarrow Z$

$$
z_{t+1}=\frac{\left(1-z_{t}\right) \varepsilon_{s, t+1}}{\left(\theta_{4}-\mu \theta_{3} \varepsilon_{s, t+1}\right)+\left(\theta_{2}+\mu \theta_{3} \varepsilon_{s, t+1}\right) z_{t}}=g\left(z_{t}, \varepsilon_{s, t+1}\right) .
$$

This is the analog of Equation (55) in Proposition 3. Any admissible sequence must lie in the set $\hat{Z} \equiv\left[z_{a}, z_{b}\right]$ where $z_{a} \equiv B_{2}^{-1}$ and $z_{b} \equiv B_{1}^{-1}$. We now show how to construct the largest set $Z \subset \hat{Z}$ such that all sequences $\left\{z_{t}\right\}$ generated by (E.6) are admissible. Note first, that

$$
\frac{\partial g\left(z, \varepsilon_{s}\right)}{\partial \varepsilon_{s}}=\frac{(1-z)\left(\theta_{4}+\theta_{2} z\right)}{\left[\left(\theta_{4}-\mu \theta_{3} \varepsilon_{s}\right)+\left(\theta_{2}+\mu \theta_{3} \varepsilon_{s}\right) z\right]^{2}},
$$

where $\theta_{4}+\theta_{2} z_{a}=B_{2}\left(1-z_{a}\right)<0$ and $\theta_{4}+\theta_{2} z_{b}=\left(1-z_{b}\right)\left[\pi B_{1}+B_{2}(1-\pi)\right]<0$. Because $z>1$, it follows that $\partial g\left(z, \varepsilon_{s}\right) / \partial \varepsilon_{s}>0$ for any $z \in\left(z_{a}, z_{b}\right)$. Moreover, 
$g\left(1, \varepsilon_{s}\right)=0$ for any $\varepsilon_{s}$. We conclude that the graph of the function $g\left(z, \varepsilon_{s}\right)$ rotates counter-clockwise around $z=1$ as $\varepsilon_{s}$ increases. The upper bound $\varepsilon_{b}$ is then obtained as the solution of the equation, $z_{b}=g\left(z_{b}, \varepsilon_{s}\right)$. A straightforward computation yields

$$
\varepsilon_{b}=\frac{z_{b}\left(\theta_{4}+\theta_{2} z_{b}\right)}{\left(1-z_{b}\right)\left(1+\mu \theta_{3} z_{b}\right)}
$$

Starting from the upper bound $\varepsilon_{b}, \varepsilon_{s}$ can be decreased down to the point where the graph of the function $g\left(z, \varepsilon_{s}\right)$ becomes tangent with the $45^{\circ}$ line. Consider the equation $g\left(z, \varepsilon_{s}\right)=z$ which can be rearranged to give the equivalent second degree polynomial

$$
z^{2}\left(\theta_{2}+\mu \theta_{3} \varepsilon\right)+z\left[\theta_{4}+\varepsilon\left(1-\mu \theta_{3}\right)\right]-\varepsilon=0 .
$$

We denote by $z_{a}^{\prime}$, the value of $z$ for which the two roots of (E.9) are equal and hence the discriminant of (E.9) is equal to zero. Equation (E.10) defines a polynomial in $\varepsilon_{s}$ such that this discriminant condition is satisfied and $\varepsilon_{a}$ is the larger of the two values of $\varepsilon_{s}$ such that this condition holds;

$$
\begin{aligned}
& {\left[\theta_{4}+\varepsilon\left(1-\mu \theta_{3}\right)\right]^{2}+4 \varepsilon\left(\theta_{2}+\mu \theta_{3} \varepsilon\right)=0, } \\
\Leftrightarrow & \varepsilon^{2}\left(1+\mu \theta_{3}\right)^{2}+2 \varepsilon\left[\theta_{4}\left(1-\mu \theta_{3}\right)+2 \theta_{2}\right]+\theta_{4}^{2}=0 .
\end{aligned}
$$

Using the formula for the roots of a quadratic, we obtain the following explicit expression for $\varepsilon_{a}$;

$$
\varepsilon_{a}=\frac{-\left[\theta_{4}\left(1-\mu \theta_{3}\right)+2 \theta_{2}\right]+\sqrt{\left[\theta_{4}\left(1-\mu \theta_{3}\right)+2 \theta_{2}\right]^{2}-\theta_{4}^{2}\left(1+\mu \theta_{3}\right)^{2}}}{\left(1+\mu \theta_{3}\right)^{2}} .
$$

This establishes the first part of Proposition 4.

We now derive an equivalent difference equation in $\tilde{Q}_{t}^{t+1}$. Here we use (E.2) and (E.3) to give the following expression for $\tilde{Q}_{t}^{t+1}$,

$$
\tilde{Q}_{t}^{t+1}=\frac{-\left(\theta_{4}-\mu \theta_{3} \varepsilon_{s, t+1}\right)-\left(\theta_{2}+\mu \theta_{3} \varepsilon_{s, t+1}\right) z_{t}}{\pi} .
$$

Rearranging (E.12) gives,

$$
z_{t}=-\frac{\left(\theta_{4}-\mu \theta_{3} \varepsilon_{s, t+1}\right)}{\left(\theta_{2}+\mu \theta_{3} \varepsilon_{s, t+1}\right)}-\frac{\pi \tilde{Q}_{t}^{t+1}}{\left(\theta_{2}+\mu \theta_{3} \varepsilon_{s, t+1}\right)} .
$$

Substitute (E.12) into (E.13) to give

$$
\tilde{Q}_{t}^{t+1}=a\left(\varepsilon_{s, t}, \varepsilon_{s, t+1}\right)+\frac{b\left(\varepsilon_{s, t}, \varepsilon_{s, t+1}\right)}{\tilde{Q}_{t-1}^{t}} \equiv h\left(\tilde{Q}_{t-1}^{t}, \varepsilon_{s, t+1}, \varepsilon_{s, t}\right),
$$

where, using the fact that $\theta_{1}+\theta_{2}+\mu \theta_{3} \equiv \theta_{2}+\theta_{4}$, we define,

$$
a\left(\varepsilon_{s, t}, \varepsilon_{s, t+1}\right) \equiv \frac{1}{\pi}\left\{\frac{\varepsilon_{s, t}\left(\theta_{2}+\mu \theta_{3} \varepsilon_{s, t+1}\right)}{\left(\theta_{2}+\mu \theta_{3} \varepsilon_{s, t}\right)}-\theta_{4}-\mu \theta_{3} \varepsilon_{s, t+1}\right\},
$$




$$
b\left(\varepsilon_{s, t}, \varepsilon_{s, t+1}\right)=\frac{1}{\pi^{2}}\left\{\frac{\varepsilon_{s, t}\left(\theta_{2}+\theta_{4}\right)\left(\theta_{2}+\mu \theta_{3} \varepsilon_{s, t+1}\right)}{\left(\theta_{2}+\mu \theta_{3} \varepsilon_{s, t}\right)}\right\} .
$$

Equation (E.14) is the analog of Equation (57). This establishes the second part of Proposition 4

\section{REFERENCES}

Abreu, D., And M. K. Brunnermeier (2003): "Bubbles and Crashes," Econometrica, 71(1), 173-204.

Allais, M. (1947): Economie et Intérêt. Imprimerie Nationale, Paris (English traduction forthcoming in 2013 at Chicago University Press).

Angeletos, G.-M., And LA'O (2013): "Sentiments," Econometrica, 81(2), 739-779.

Azariadis, C. (1981): "Self-fulfilling Prophecies," Journal of Economic Theory, 25(3), 380-396.

Barberis, N., And R. Thaler (2003): "A Survey of Behavioral Finance," in Handbook of the Economics of Finance, ed. by R. Stulz, and M. Harris. Noth Holland, Amsterdam.

Barsky, R. B., And J. B. DeLong (1993): "Why Does the Stock Market Fluctuate," Quarterly Journal of Economics, 107, 291-311.

Benhabib, J., and R. E. A. Farmer (1994): "Indeterminacy and Increasing Returns," Journal of Economic Theory, 63, 19-46.

Benhabib, J., P. Wang, and Y. Wen (2012): "Sentiments and Agregate Fluctuations," NBER working paper 18413.

Bernanke, B., M. Gertler, and S. Gilchrist (1996): "The Financial Accelerator and the Flight to Quality," The Review of Economics and Statistics, 78(1), $1-15$.

Bernanke, B. S., and M. Gertler (1989): "Agency Costs, Net Worth and Business Fluctuations," American Economic Review, 79(1), 14-31.

(2001): "Should Central Banks Respond to Movements in Asset Prices?," American Economic Review, 91(2), 253-257.

Blanchard, O. J. (1985): "Debt, Deficits, and Finite Horizons," Journal of Political Economy, 93(April), 223-247.

Brunnermeir, M. K. (2012): "Macroeconomics with Financial Frictions," in Advances in Economics and Econometrics. Cambridge University Press.

Brunnermeir, M. K., and Y. Sannikov (2012): "Redistributive Monetary Policy," Paper presented at the 2012 Jackson Hole Conference, August 31st - September 2nd 2012. 
Bullard, J., G. Evans, and S. Honkapohja (2010): "A Model of Near-Rational Exuberance," Macroeconomic Dynamics, 14, 106-88.

Caballero, R. J., and A. Krishnamurthy (2006): "Bubbles and Capital Flow Volatility: Causes and Risk Management," Journal of Monetary Economics, 53(1), $35-53$.

Campbell, J. Y., and J. H. Cochrane (1999): "By Force of Habit: A Consumption-Based Explanation of Aggregate Stock Market Behavior," Journal of Political Economy, 107, 205-251.

Carlstom, C., and T. S. Fuerst (1997): "Agency Costs, Net Worth and Business Fluctuations: A Computable General Equilbrium Analysis," American Economic Review, 87(5), 893-910.

CAss, D. (1965): "Optimum Growth in an Aggregative Model of Capital Accumulation," Review of Economic Studies, 32, 233 - 240.

Cass, D., and K. Shell (1983): "Do Sunspots Matter?," Journal of Political Economy, 91, 193-227.

Christiano, L., R. Motto, and M. Rostagno (2012): "Risk Shocks," Northwestern University mimeo.

Cochrane, J. H. (2011): "Presidential Adress: Discount Rates," The Journal of Finance, 66(4), 1047-1108.

Eggertsson, G. (2011): "What Fiscal Policy is Effective at Zero Interest Rates?," in NBER Macroeconomics Annual 2010, vol. 25, pp. 59-112. National Bureau of Economic Research Inc.

Eggertsson, G. B., and M. Woodford (2002): "The Zero Bound on Interest Rates and Optimal Monetary Policy," Brookings Papers on Economic Activity, 2, 139-211.

Epstein, L., And S. Zin (1989): "Substitution, Risk Aversion and the Temporal Behavior of Consumption and Asset Returns: An Empirical Analysis," Journal of Political Economy, 99, 263-286.

(1991): "Substitution, Risk Aversion and the Temporal Behavior of Consumption and Asset Returns: A Theoretical Framework," Econometrica, 57, 937969.

Fahri, E., and J. Tirole (2012): "Bubbly Liquidity," The Review of Economic Studies, 79(2), 678-706.

FAma, E. F. (1963): "Mandelbrot and the Stable Paretian Hypothesis," Journal of Business, 36, 420-429. 
- (1965a): "The Behavior of Stock Market Prices," Journal of Business, 38, 34-105.

— (1965b): "Random Walks in Stock Market Prices," Financial Analysts Journal, 21, 55-59.

- (1970): "Efficient Capital Markets: A Review of Theory and Empirical Work," Journal of Finance, 25(2), 383-417.

Farmer, R. E. A. (1999): The Macroeconomics of Self-Fulfilling Prophecies. MIT Press, Cambridge, MA, second edn.

- (2002a): "Business Cycles with Heterogeneous Agents," UCLA mimeo, Paper prepared for a conference at GREQAM on "New Perspectives of (In)Stability, the Role of Heterogeneity", Marseilles, June 2011.

— (2002b): "Fiscal Policy, Equity Premia, and Heterogeneous Agents," UCLA mimeo, Paper presented to the conference "New Developments in Fiscal Policy Analysis" at Universitat Pompeu Fabra, Barcelona, May 2002.

- (2010): Expectations, Employment and Prices. Oxford University Press, New York.

(2012a): "Confidence, Crashes and Animal Spirits," Economic Journal, $122(559)$.

- (2012b): "Qualitative Easing: How it Works and Why it Matters," NBER working paper 18421 and CEPR discussion paper 9153.

- (2012c): "The Stock Market Crash of 2008 Caused the Great Recession: Theory and Evidence," Journal of Economic Dynamics and Control, 36, 697-707. - (2013): "Animal Spirits, Financial Crises and Persistent Unemployment," Economic Journal, 123(568).

— (2014): "The Evolution of Endogenous Business Cycles," Macroeconomic Dynamics, (forthcoming).

Farmer, R. E. A., and J. T. Guo (1994): "Real Business Cycles and the Animal Spirits Hypothesis," Journal of Economic Theory, 63, 42-73.

Farmer, R. E. A., C. Nourry, and A. Venditti (2011): "Debt Deficits and Finite Horizons, the Stochastic Case," Economics Letters, 111, 47-49.

Farmer, R. E. A., and D. Plotnikov (2012): "Does Fiscal Policy Matter? Blinder and Solow Revisited," Macroeconomic Dynamics, 16(Supplement 1), 149-166.

Farmer, R. E. A., and M. Woodford (1984): "Self-fulfilling Prophecies and the Business Cycle," Caress Working Paper 84-12.

- (1997): "Self-fulfilling Prophecies and the Business Cycle," Macroeconomic Dynamics, 1(4), 740-769. 
Fostel, A., and J. Geanakoplos (2008): "Leverage Cycles and the Anxious Economy," American Economic Review, 98(4), 1211-1234.

Fox, J. (2009): The Myth of the Rational Market. Harper Collins.

Futia, C. A. (1982): "Invariant Distributions and the Limiting Behavior of Markovian Economic Models," Econometrica, 50(2), 377-408.

Geanakoplos, J. (2010): "The Leverage Cycle," in NBER Macroeconomics Annual 2009, ed. by D. Acemoglu, K. Rogoff, and M. Woodford. University of Chicago Press.

Gu, C., And R. Wright (2010): "Endogenous Credit Cycles," University of Wisconsin, mimeo.

Kiyotaki, N., And J. H. Moore (1997): "Credit Cycles," Journal of Political Economy, 105(3), 739-764.

Koopmans, T. C. (1965): "On the Concept of Optimal Economic Growth," in The Econometric Approach to Development Planning, pp. 225-300. North Holland.

Lansing, K. J. (2010): "Rational and Near-Rational Bubbles Without Drift," Economic Journal, 549, 1149-1174.

Leroy, S., And R. Porter (1981): "Stock Price Volatility: A Test based on Implied Variance Bounds," Econometrica, 49, 97-113.

Malinvaud, E. (1987): "The Overlapping Generations Model in 1947," Journal of Economic Literature, 25, 103-105.

Malloy, C. J., T. J. Moskowitz, and A. Vissing-Jorgensen (2009): "LongRun Stockholder Consumption Risk and Asset Returns," The Journal of Finance, 64(6), 2427-2479.

Martin, A., And J. Ventura (2011): "Theoretical Notes on Bubbles and the Current Crisis," IMF Economic Review, 59(1), 6-40.

(2012): "Economic Growth with Bubbles," American Economic Review, 102(6), 3033-3058.

Miao, J., And P. Wang (2012): "Bubbles and Total Factor Productivity," American Economic Review: Papers and Proceedings, 102(3), 82-87.

Oreopoulos, P., T. Von-Wachter, and A. Heisz (2012): "The Short- and LongTerm Career Effects of Graduating in a Recession: Hysteresis and Heterogeneity in the Market for College Graduates," American Economic Journal: Applied Economics, 4(1), 1-29.

Plotnikov, D. (2012): "Hysterisis in Unemployment and Jobless Recoveries," mimeo, UCLA. 
Ramsey, F. P. (1928): "A Mathematical Theory of Saving," Economic Journal, Vol. 38, No 152, pp.543-559, 38(152), 543-559.

Rochetau, G., and R. Wright (2010): "Liquidity and Asset Market Dynamics," University of Wisconsin mimeo.

Samuelson, P. A. (1963): "Proof that Properly Anticipated Prices Fluctuate Randomly," Industrial Management Review, 6, 41-49.

Shell, K. (1971): "Notes on the Economics of Infinity," Journal of Political Economy, 79, 1002-1011.

Shiller, R. J. (1981): "Do Stock Prices Move too Much to be Justified by Subsequent Changes in Dividends?," American Economic Review, 71, 421-436.

Stokey, N. L., R. E. Lucas, Jr., and w. E. C. Prescott (1989): Recursive Methods in Economic Dynamics. Harvard University Press, Cambridge, MA.

Thaler, R. (2009): "Markets can be Wrong and the Price is not Always Right," Financial Times, August 4th.

Wen, Y. (1998): "Capacity Utilization under Increasing Returns to Scale," Journal of Economic Theory, 81(1), 7-36.

UClA, Aix-Marseille University (Aix-Marseille School of Economics), CNRSGREQAm, EHESS, and Aix-Marseille University (Aix-Marseille School of EconomICS), CNRS-GREQAM, EHESS \& EDHEC 